\title{
Stochastic Idiosyncratic Operating Risk and Real Options: Implications for Stock Returns
}

\author{
Harjoat S. Bhamra* \\ Imperial College Business School
}

\author{
Kyung Hwan Shim ${ }^{\dagger}$ ‡ \\ University of New South Wales
}

First Draft:

November 19, 2012

This Version:

January 20, 2015

\begin{abstract}
We show that introducing stochastic idiosyncratic operating risk into an equity valuation model of firms with growth options explains two empirical results related to idiosyncratic volatility: the positive contemporaneous relation between stock returns and changes in idiosyncratic return volatility, and the poor performance of stocks with high idiosyncratic volatility. The model further predicts that (i) returns correlate positively with idiosyncratic volatility during intervals between large changes in idiosyncratic volatility (the switch effect), (ii) and that the return relations and the switch effect are stronger for firms with more real options and which undergo larger changes in idiosyncratic volatility. Empirical results support these predictions.
\end{abstract}

Keywords: Idiosyncratic return volatility, cross section of stock returns, asset pricing, real options, growth options, stochastic volatility, regime switching, mixed jump-diffusion processes.

*Imperial College Business School, London, UK, SW7 2AZ, Email: bhamra.harjoat@gmail.com; Tel: +44 (0)20 7594 9077.

${ }^{\dagger}$ School of Banking and Finance, Australian School of Business, University of New South Wales, Sydney NSW, Australia, 2052, Email: k.shim@unsw.edu.au; Tel: 61 (02) 93855852.

${ }^{\ddagger}$ We would like to thank Efstathios Avdis, Tony Berrada, George Constantinides, Lorenzo Garlappi, Ralph Koijen, Chunhua Lan, Andrey Malenko, Stijn Van Nieuwerburgh, Stavros Panageas, Konark Saxena, Paul Schneider, Mark Shackleton, Robert Tumarkin, Raman Uppal, Jin Yu, Tan Wang, seminar participants at the University of New South Wales, University of Southern California, Norwegian School of Economics (Bergen), McGill University, Nottingham University Business School, Carleton University, participants of the 2013 Adam Smith Asset Pricing Conference, the 2013 China International Conference in Finance, the 2013 Northern Finance Association Annual Meetings, the 2013 Tel Aviv University Finance Conference, the 2014 Frontiers of Finance, the 2014 European Finance Association Annual Meetings and the 2015 American Finance Association Annual Meetings for helpful comments and discussions. We would also like to thank the Canadian Institute of Chartered Business Valuators for the Best Paper Award at the 2013 NFA Annual Meetings. All errors are ours. Please forward comments and suggestions to k.shim@unsw.edu.au. 


\section{Introduction}

Modern portfolio theory and the capital asset pricing model suggest that investors diversify idiosyncratic risks and only systematic risk is priced in equilibrium. The empirical evidence on idiosyncratic return volatility $(I V o l)$ and stock returns is not readily explained by this simple

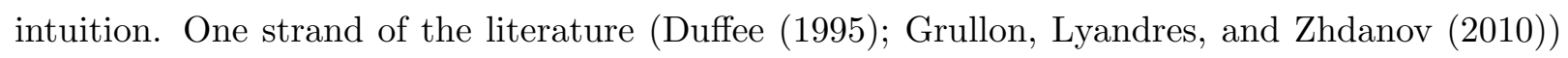
establishes that changes in monthly realized $I V o l$ are contemporaneously positively related with stock returns (positive IVol-return relation hereafter), while a different strand (Ang, Hodrick. Xing, and Zhang (2006) ) establishes that portfolios of high end-of-month $I V$ ol stocks significantly under-perform their low $I V o l$ counterparts (negative $I V$ ol-return relation hereafter). ${ }^{1}$ Yet, a third strand of the literature establishes that the negative $I V o l$-return relation is due to strong return

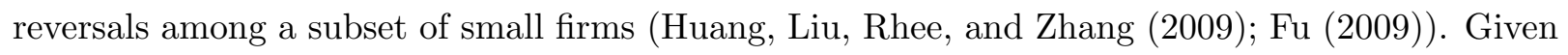
the lack of consensus, it is not surprising that progress in delivering a unified explanation for these findings has been difficult. ${ }^{2}$

In this paper, we reconcile these seemingly disparate empirical regularities via an equity valuation model with real options and stochastic idiosyncratic operating risk captured by switches in regimes. ${ }^{3}$ Our model also provides novel empirical predictions, which are borne out in the data, thereby providing evidence that our choice of model is reasonable. We start by showing that if a firm's equity returns possess two key properties, then the positive and negative IVol-return relations can be resolved. This is true even if the CAPM holds. The first property is that a firm's equity returns and its idiosyncratic volatility are driven by a common idiosyncratic risk factor and the second is that a firm's systematic volatility falls when idiosyncratic risk increases. The first property ensures that firm-level abnormal returns and changes in idiosyncratic risk are positively correlated, which is the positive $I V$ ol-return relation. The second property ensures firm-level expected returns, which load on systematic volatility are higher when idiosyncratic risk is lower,

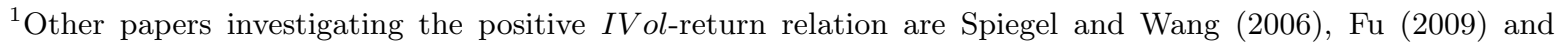
Huang, Liu, Rhee, and Zhang ( $\mathbb{2 0 0 9})$. The negative IVol-return relation is also shown to exist in international stock markets by Ang, Hodrick, Xing, and Zhang (밈).

${ }^{2}$ Earlier empirical papers investigating idiosyncratic volatility and returns in the cross section are एintnen (ए96.) एinic and West (एप86) and एehmand (멈).

${ }^{3}$ Starting from a partial equilibrium valuation model with real options similar to Carlson, Fisher, and Gi ammarind (2004) and Cooper ( $\mathbb{2 0 0 7}$ ), we introduce stochastic idiosyncratic operating risk, for which we assume a 2-regime Markov switching process. Guo, Miao, and Morelled (2005) and Hackbarth, Miao, and Morelled (2006) also develop a 2-regime Markov switching process in state dynamics to investigate investment and capital structure decisions, respectively.
} 
giving rise to the negative $I V$ ol-return relation. In our theoretical model of a cross-section of firms with growth options, where idiosyncratic operating risk is stochastic, both properties arise endogenously - this resolves the positive and negative IVol-return relations. We exploit the analytical solutions of the model to validate our theoretical analysis via simulation. Using simulated data we redo the main analysis in Duffed ([י995) and Ang, Hodrick, Xing, and Zhang (2006)) - we thereby verify that our model, in which the CAPM holds, does indeed resolve both the positive and negative $I V o l$-return relations. Finally, to test whether our choice of model is reasonable, we identify its novel empirical predictions and confront them with the data.

We now explain how a cross-sectional model of firms with growth options and stochastic idiosyncratic operating risk gives rise to firm-level equity returns, which possess the two key properties which allow the resolution of the positive and negative $I V o l$-return relation. A firm's currently producing assets - the assets-in-place - have linear valuations in cashflows, which are invariant with respect to idiosyncratic operating risk. In contrast, a firm's growth options are convex with respect to cashflows and therefore depend on idiosyncratic operating risk. Standard option pricing theory tells us options are levered positions on the underlying asset - an increase in the volatility of the underlying asset increases the option value. Therefore returns on a firm with growth options will be exposed to the same underlying idiosyncratic risk factor as the level of idiosyncratic risk itself - this is just the first key property, and so firm-level returns will be positively correlated with changes in $I V o l$. Idiosyncratic risk is by definition non-systematic, and so the increase in growth option and hence firm value stemming from a rise in idiosyncratic risk will be accompanied by a decrease in the proportion of the option value exposed to systematic risk. Hence, the second key property is satisfied: systematic risk falls as idiosyncratic risk rises. ${ }^{4}$ Expected returns load on systematic risk, so a firm with growth options will have expected returns which fall when idiosyncratic risk rises, resolving the negative $I V o l$-return relation.

To verify the intuition revealed by our theoretical analysis, we simulate the model. ${ }^{5}$ The simulations recreate the $I V$ ol-return relations that are qualitatively similar to Duffed ([प995) and Ang, Hodrick, Xing, and Zhang (ए006), with more pronounced results when we specify larger

\footnotetext{
${ }^{4}$ This is in contrast with the embodied technology shocks modelled in Garleanu, Panageas, and Yu (एणए), which impact the level of output flow.

${ }^{5}$ By using a 2-regime Markov switching process to model idiosyncratic operating risk, we can derive analytical solutions (see Guo, Miao, and Morelleg (200) and Hackbarth, Miao, and Morelled (एण06)).
} 
spreads in volatility between regimes. When we specify a single regime - the standard specification in most real option models - we find that the model generates no statistical $I V$ ol-return relation, validating that our explanation is the driving mechanism behind the results.

Our model also helps understand the findings that the negative $I V$ ol-return relation is largely explained by the return reversals of high $I V$ ol stocks among a subset of small firms \#uang.

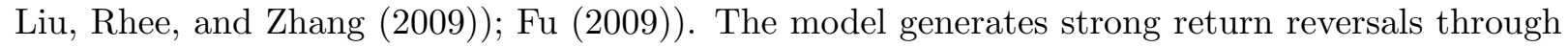
the risk dynamics embedded in the operations of the firms that possess growth opportunities. Therefore, we rely on a rational theory of firms that face uncertain operating environments which allows for observable firm-characteristics to explain dispersions in equity returns. In this sense, we

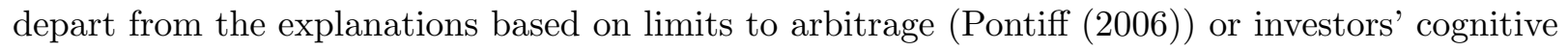
biases and mispricings in financial markets (Daniel, Hirshleifer, and Subrahmanyam (एपपष)) for the negative $I V o l$-return relation.

The final part of our paper is empirical - is the data supportive of the key economic mechanisms in our theoretical model? To answer this question, we test the model's novel empirical predictions. First, we focus on verifying the model's predictions that the IVol-return relations rely on real options and idiosyncratic operating risks. This is crucial for verifying the economics underlying our explanation for how the $I V$ ol-return relations can arise in a rational model. For the positive IVol-return relation, we revisit Grullon, Lyandres, and Zhdanov (2010) by recreating many of their empirical proxies for real options - and some of our own - and employing similar crosssectional return regressions. Additionally, we expand on Grullon, Lyandres, and Zhdanov (2000) with new regression specifications in which we include the difference between the 70th and 30th percentile values of $I \mathrm{Vol}$ for each stock as a proxy for the variability in idiosyncratic volatility to test the novel predictions of our model. For the negative $I V o l$-return relation, we initially follow Ang, Hodrick, Xing, and Zhang (एण06) by creating IVol-sorted portfolios, and then go further by sorting stocks via proxies for real option intensity and variability in $I V$ ol to compute portfolio returns. We find evidence for stronger positive and negative $I V o l$-return relations for more real option intensive firms and which experience more extreme changes in IVol. These results lend strong support to our model.

We also focus our empirical analysis on a novel set of empirical predictions. Conditioned on a volatility regime, expected equity returns equate to the sum of a continuous drift term 
and a jump term that captures the expectation of a change in equity value in the event of a switch in volatility. Consider a firm that experiences an increase in idiosyncratic operating risk. Pre-jump the firm experiences relatively low returns driven by the nonmaterialized potential for positive jump in idiosyncratic volatility; and similarly, the firm experiences relatively high post-jump returns driven by nonmaterialized negative jumps in idiosyncratic volatility. Hence, if real options and stochastic idiosyncratic risk are incorporated into firm valuations, stock returns should correlate positively with $I V o l$ in intervals between large changes in $I V o l$. Using an event study approach, we investigate the difference in 5-month average returns around the month in which stocks experience large changes in $I V o l$. We find that the difference between post and pre-switch returns is positive for the up-switch sample, and negative for the down-switch sample, and that this 'switch effect' is stronger for firms with more real options or which experience more extreme changes in $I V o l$. Here again the results are in strong agreement with the model.

Motivated by anomalies evidenced in the cross-section of stock returns, Berk, Green, and Naik ([प999) were among the first to establish a linkage between corporate investments and expected equity returns. ${ }^{6,7}$ Since then, the literature has been extended in many directions (Carlson, Fisher.

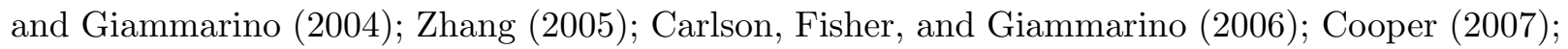
Sagi and Seashold (एण07), and Carlson, Fisher, and Giammaring (एण0])). We add to this literature by expanding the description of the firm's operating environment to reconcile the $I V$ ol-return relations. In our model, idiosyncratic volatility serves as an additional state variable that affects only the systematic volatility of a firm's real options, but not assets-in-place.

To the best of our knowledge few inroads have been made to link idiosyncratic risk to asset pricing. The exceptions are Babenko, Boguth, and Tserlukevich (2013) and Kogan and Papanikolaou (सणत) who show that firm-specific shocks contain information about future priced risk. Babenko et ad (एण.3) view firms as portfolios of systematic and idiosyncratic divisions and rely on additive systematic and idiosyncratic cashflow shocks in the valuation of the firms. $\mathbb{K} 0$ gan and Papanikolaou (2013), on the other hand, show that the investments of firms with high

${ }^{6}$ Eama and French (एप9प2) provide evidence on the ability of size and book-to-market to explain returns. Eama andFrench ([1996) provide a cross-sectional landscape view of how average returns vary across stocks. Anderson and Garcia-Feijo0 (2006) offer empirical evidence on the relation between corporate investments and average returns.

${ }^{7}$ Firm-level investment in a real option context was first pioneered by MacDonald and Siegel (एप8. ), MacDonald and Siegel (एप86) and Brennan and Schwart] (एप8. $)$, and later adopted and extended by many others. Dixit and Pindyck (एप.94) is a standard reference for a detailed analysis of the literature. 
growth opportunities exhibit higher sensitivity to investment-specific-technology shocks earning a lower risk premia. While one can view these models as strongly complementary, our modeling approach explicitly considers idiosyncratic cashflow shocks with time-varying risk together with an optimal timing decision concerning growth option exercise. Hence, the underlying mechanism

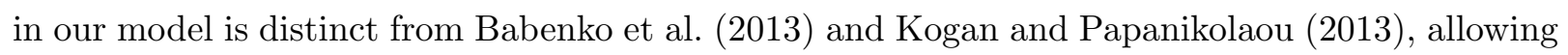
us to propose a novel channel between the operating environment faced by the firms and equity returns. The distinct features of our model yield novel testable predictions on the correspondence between $I V o l$ and stock returns such as the switch effect, which we test empirically in this paper.

The rest of the paper is organized as follows. In Section 2, we describe two key properties of equity returns, which are sufficient to resolve the positive and negative $I V o l$-return relations. In Section 3, we describe the model and provide analytical solutions to show that the two key properties arise endogenously. In Section 4, we redo the main analysis of Duffed (एप9.5) Ang, Hodrick, Xing, and Zhang ( $(2006)$, but with simulated data from the model, to show that the positive and negative $I V o l$-return relations arise within the model. We take the novel empirical predictions of our model and confront them with the data in Section 5 and in Section 6 we conclude. The Appendix contains all the proofs and other technical details omitted in the main body of the paper.

\section{Two Key Properties of Returns: A Thought Experiment}

In this section we describe two properties of returns which lead to the positive $I V$ ol-return relation, i.e. the positive contemporaneous relation between stock returns and changes in idiosyncratic return volatility, and the negative $I V o l$-return relation, i.e. the poor performance of stocks with high idiosyncratic volatility.

We first assume the existence of a stochastic discount factor (SDF), $\pi$, such that

$$
\frac{d \pi_{t}}{\pi_{t}}=-r_{t} d t-\Theta_{t} d B_{t}^{s y s}
$$

The riskfree rate $r_{t}$ may be stochastic, $d B_{t}^{s y s}$ is a composite systematic risk factor, and $\Theta_{t}$ is the 
composite price of risk, which can be decomposed as follows:

$$
d B_{t}^{s y s}=\sum_{n=1}^{N} \frac{\Theta_{n, t}}{\Theta_{t}} d B_{n, t}^{s y s}, \Theta_{t}=\sqrt{\sum_{n=1}^{N} \Theta_{n, t}^{2}},
$$

where $B_{n, t}^{\text {sys }}, i \in\{n, \ldots N\}$ are mutually orthogonal standard Brownian motions under the physical probability measure $\mathbb{P}$, each corresponding to some risk factor, where $\Theta_{i, t}$ is the associated price of risk, which can be stochastic. This way we make it clear that (ש.]) nests models such as Bansal and Yaron (2004), where the conditional CAPM does not hold in addition to the conditional CAPM.

Equity returns on a cross-section of firms, $k \in\{1, \ldots, K\}$ are exposed to aggregate risk and idiosyncratic risk. The equity return for Firm $k$ is given by

$$
d R_{k, t}=\mu_{t} d t+\sigma_{t}^{s y s} d B_{t}^{s y s}+\sigma_{k, t}^{i d} d M_{k, t}^{i d}
$$

where the conditional expected return, $\mu_{t}$, may be stochastic, $\sigma_{t}^{s y s}$ is conditional systematic volatility, which can be stochastic, $d M_{k, t}^{i d}$ is the increment in some idiosyncratic risk factor for Firm $k$ and $\sigma_{k, t}^{i d}$ is conditional idiosyncratic volatility, which we assume is positive for all firms. The idiosyncratic risk factors are independent across firms and so is conditional idiosyncratic volatility. 8

Since $\pi$ is a SDF, the basic asset pricing equation holds, i.e.

$$
E_{t}\left[d R_{k, t}-r_{t} d t\right]=E_{t}\left[d R_{k, t} \frac{d \pi_{t}}{\pi_{t}}\right]
$$

which implies

$$
\mu_{t}=r_{t}+\sigma_{t}^{\text {sys }} \Theta_{t}
$$

So far everything has been standard - we have not yet made any novel assumptions. We now do so by assuming returns for firms $k \in\{1, \ldots, K\}$ satisfy the following two properties:

Property 1 The idiosyncratic risk factor for Firm k's returns is also a risk factor for the firm's

\footnotetext{
${ }^{8} M_{k, t}^{i d}$ is a martingale under the physical probability measure $\mathbb{P}$ and may be continuous, e.g. a standard Brownian motion or discontinuous such as a compensated Poisson process.
} 
idiosyncratic volatility, i.e.

$$
d \sigma_{k, t}^{i d}=a_{t} d t+b_{t} d M_{k, t}^{i d}
$$

where $b_{t}>0$.

Property 2 Firm k's systematic volatility is a decreasing function of its idiosyncratic volatility.

We now explore the implications of Properties 1 and 2 for $I V$ ol-return relations via a simple thought experiment.

In the first part of our thought experiment, we ask what would happen if we simulated returns and idiosyncratic volatility and ran a regression of monthly abnormal returns against corresponding monthly changes in volatility? We would find a positive relationship between monthly abnormal returns and changes in idiosyncratic volatility, i.e. the positive $I V$ ol anomaly would hold. Why is this so? The answer lies in Property $\square$.

The dynamics of abnormal returns are given by

$$
d R_{k, t}^{a}=\sigma_{t}^{s y s} d B_{t}^{s y s}+\sigma_{k, t}^{i d} d M_{k, t}^{i d}
$$

There is a single common risk factor driving both abnormal returns and changes in idiosyncratic volatility. Furthermore, the direction of the changes is the same. The only other risk factor driving abnormal returns is the systematic risk factor, which is independent of changes in idiosyncratic volatility. There are no additional risk factors driving changes in idiosyncratic volatility. Hence, abnormal returns and changes in idiosyncratic volatility will be positively correlated.

To see this more formally, observe that a monthly abnormal return is given by

$$
R_{k, t+\frac{1}{12}}^{a}-R_{k, t}^{a}=\int_{t}^{t+\frac{1}{12}} d R_{k, u}^{a} d u=\int_{t}^{t+\frac{1}{12}} \sigma_{u}^{s} d B_{u}^{s y s}+\int_{t}^{t+\frac{1}{12}} \sigma_{k, u}^{i d} d M_{k, u}^{i d}
$$

The corresponding monthly change in idiosyncratic volatility is given by

$$
\sigma_{k, t+\frac{1}{12}}^{i d}-\sigma_{k, t}^{i d}=\int_{t}^{t+\frac{1}{12}} d \sigma_{k, u}^{i d} d u=\int_{t}^{t+\frac{1}{12}} a_{u} d u+\int_{t}^{t+\frac{1}{12}} b_{u} d M_{k, u}^{i d} d u
$$

The conditional covariance between abnormal returns and the corresponding change in idiosyn- 
cratic volatility is clearly positive:

$$
\operatorname{Cov}_{t}\left(R_{k, t+\frac{1}{12}}^{a}-R_{k, t}^{a}, \sigma_{k, t+\frac{1}{12}}^{i d}-\sigma_{k, t}^{i d}\right)=E_{t}\left[\left(\int_{t}^{t+\frac{1}{12}} \sigma_{k, u}^{i d} d M_{k, u}^{i d}\right)\left(\int_{t}^{t+\frac{1}{12}} b_{u} d M_{k, u}^{i d} d u\right)\right]>0 .
$$

There is therefore a positive contemporaneous relationship between returns and $I V o l$ at the firm level. Of course, idiosyncratic volatility cannot be observed directly, but if we could estimate it sufficiently accurately via observing abnormal returns, then we would still expect to find the positive $I V$ ol-return relation.

The second part of our thought experiment relates to the second property of returns. We observe returns data over a month, measure the variance of their abnormal returns as a proxy for idiosyncratic volatility, sort firms by their estimated idiosyncratic volatility and then observe their returns over the next month. How would such portfolios perform over the next month, if we measure performance in terms of returns?

To answer this question consider a firm for which idiosyncratic volatility is currently high. The expected return for a firm is given by

$$
E_{t}\left[d R_{k, t}\right]=\left(r_{t}+\sigma_{t}^{\text {sys }} \Theta_{t}\right) d t
$$

where by assumption $\sigma_{t}^{\text {sys }}$ is a decreasing function of $\sigma_{k, t}^{i d}$. Hence, expected returns will be lower for higher $I V o l$ portfolios: the negative $I V o l$-return relation arises naturally from Property $\square$.

An obvious concern comes to mind. Is the example behind our thought experiment pathological or can the two key properties we have used arise naturally in a standard cross-sectional asset pricing model?

In the next section we show the two key properties are not at all pathological. On the contrary, they arise as endogenous outcomes in a model of a cross-section of firms with growth options provided we make a single crucial assumption: idiosyncratic operating risk is stochastic. 


\section{Model}

We construct a growth option model similar in spirit to the models in Garlappi and Yan (खण्]) and Carlson, Fisher, and Giammarino (2004) ${ }^{9}$ This section describes the firms' economic environment.

\subsection{The Environment}

There are two types of firms: mature and young, and there is a finite number of each. Mature firms produce at full capacity. In contrast, young firms produce at a lower operating scale, but have the option to make an irreversible investment to increase production and also become mature. Firms are all equity financed. Firm $k$ produces a single commodity that can be sold at time- $t$ in the product market at price $P_{k, t}$, with dynamics

$$
P_{k, t}=X_{k, t} Z_{t}
$$

where $X_{k}$ and $Z$ are respectively the idiosyncratic and systematic components. Their dynamics are given by

$$
\begin{aligned}
\frac{d X_{k, t}}{X_{k, t}} & =\sigma_{k, t}^{i d} d B_{k, t}^{i d}, \\
\frac{d Z_{t}}{Z_{t}} & =\mu d t+\sigma^{s y s} d B_{t}^{s y s},
\end{aligned}
$$

$\mu$ denotes the constant growth rate, $\sigma^{s y s}$ constant systematic volatility, $\sigma_{k, t}^{i d}$ stochastic idiosyncratic volatility, and $d B_{k, t}^{i d}$ and $d B_{t}^{s y s}$ are the increments of two independent Brownian motions. The increments $d B_{k, t}^{i d}$ are independent across firms.

The presence of uncertainty shocks (see for example Bloom (2009)) in the idiosyncratic component of the volatility of price growth is the novel feature of our model. In other words, idiosyncratic operating risk is stochastic. The economic rationale for our assumption comes from allowing firms to have random and time-varying potential to realize monopolistic rents. ${ }^{10}$

\footnotetext{
${ }^{9}$ With no loss of generality, we rely specifically on growth options to incorporate convexity of firm valuations in the firms' output price. Other forms of real options that incorporate convexities would accommodate similar results.

${ }^{10}$ Dixit and Pindyck ([प94) and Caballero and Pindyck (एपYG) show that idiosyncratic shocks translate to a firm's ability to retaining monopolistic rents - a firm that experiences a positive idiosyncratic technology shock
} 
We model shocks to Firm $k$ 's idiosyncratic volatility by assuming $\sigma_{k, t}^{i d}$ follows a 2 -state Markov chain: $\sigma_{k, t}^{i d} \in\left\{\sigma_{L}^{i d}, \sigma_{H}^{i d}\right\}$, where $0<\sigma_{L}^{i d}<\sigma_{H}^{i d}$ and the probability of entering state $s_{k, t} \in\{L, H\}$ within the infinitesimally small time $d t$ is $\lambda_{s_{k, t}} d t{ }^{11}$ Firms do not have to be in the same idiosyncratic volatility state and switches between states are independent across firms. Essentially, each firm has its own idiosyncratic volatility state and Markov chain, which is i.i.d. across firms hence the appearance of the subscript $k$ on $\sigma_{k, t}^{i d}$ and $s_{k, t}$, but not on $\sigma_{L}^{i d}$ and $\sigma_{H}^{i d}$. Both $P_{k, t}$ and the volatility regime $s_{k, t}$ are observable for any given firm. We subscript quantities with $s_{k, t} \in\{H, L\}$ throughout to denote their dependence on Firm $k$ 's volatility regime.

Investors in the stock market can hedge market risk in the firms' operations by trading on two securities. Let $B_{t}$ denote the price of the risk free asset with dynamics

$$
\frac{d B_{t}}{B_{t}}=r d t
$$

where $r$ is the constant riskless rate and let $S$ be the price of a risky security with dynamics

$$
\frac{d S_{t}}{S_{t}}=\mu_{S} d t+\sigma_{S} d B_{t}^{s y s}
$$

$S$ has a beta equal to one and $\Theta=\frac{\mu_{S}-r}{\sigma_{S}}$ is the constant market price of risk. The proportion of $S$ held in a replicating portfolio determines the beta of the portfolio. This is equivalent to assuming an exogenous stochastic discount factor $\pi$, where

$$
\frac{d \pi_{t}}{\pi_{t}}=-r d t-\Theta d B_{t}^{s y s}
$$

It is important to note that the risk-free rate and market price of risk are constant - this is purely for clarity. We could accommodate both a stochastic risk-free rate and market price of risk. However, we choose not to, because they are not central to the economics underlying this paper.

We can carry out the valuation of firms under the risk-neutral measure $\mathbb{Q}$. Working under $\mathbb{Q}$

experiences an advantage that cannot be stolen by its competitors, while a positive aggregate shock is shared with the firm's competitors. Some plausible micro-economic examples for a change in idiosyncratic operating risk are: shifts in consumer needs and wants, persistent changes in production technology, or changes in the general operating environment of the firm or the firm's industry, among others.

${ }^{11}$ Using a Markov chain with more than 2 states is also possible, but does not add to the underlying economics. 
changes the dynamics of the systematic component of the product market price to

$$
\frac{d Z_{t}}{Z_{t}}=\hat{\mu} d t+\sigma^{s y s} d \hat{B}_{t}^{s y s}
$$

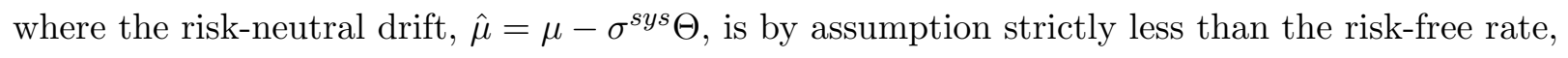
$r$, and $d \hat{B}_{t}^{\text {sys }}=\Theta d t+d B_{t}^{\text {sys }}$ is the increment in a standard Brownian motion under $\mathbb{Q}$.

\subsection{The Value of a Mature Firm}

We now derive the value of a mature firm. We shall omit firm subscripts throughout the rest of this section for convenience.

The cash flow of a mature firm stems solely from its assets-in-place, which allow it to create output. Consider assets-in-place which produce a unit of output per unit time. The cost of producing a unit of output is $c$ per unit of time and so the profit per unit time is $P_{t}-c$. The value of the profit stream stemming from producing a unit of output is

$$
A_{t}=A\left(P_{t}\right)=E_{t}^{\mathbb{Q}}\left[\int_{t}^{\infty} e^{-r(u-t)}\left(P_{u}-c\right) d u\right]=\frac{P_{t}}{r-\hat{\mu}}-\frac{c}{r}
$$

The scale of production for a mature firm is $\xi_{M}$, and so its profit flow is $\xi_{M}\left(P_{t}-c\right)$. The value of a mature firm is therefore given by $\xi_{M} A_{t}$.

\subsection{The Value of a Young Firm}

A young firm derives value from the sum of its assets-in-place and a growth option.

The value of assets-in-place for a young firm is smaller than for mature firm, because of a smaller production scale, $\xi_{Y}<\xi_{M}$. The value of a young firm's assets-in place is thus given by $\xi_{Y} A_{t}$.

A growth option allows a young firm to increase its production scale by $\xi=\xi_{M}-\xi_{Y}$. Hence, at the moment of exercise, $\tau$, the value of the young firm's assets-in-place increases by $\left(\xi_{M}-\xi_{Y}\right) A_{\tau}=$ $\xi A_{\tau}$. At the moment of exercise, the young firm pays a one time irreversible investment of $I$. The expected present-value of the payoff $\xi A_{\tau}-I$ gives the value of the growth option

$$
G_{s_{t}}=G_{s_{t}, t}=E_{t}^{\mathbb{Q}}\left[e^{-r(\tau-t)}\left(\xi A_{\tau}-I\right) \mid s_{t}\right], t \leq \tau,
$$


which depends on the volatility regime. This is indicated by $E_{t}^{\mathbb{Q}}\left[\cdot \mid s_{t}\right]$, the expectation operator under $\mathbb{Q}$ conditional on date- $t$, when the current volatility regime is $s_{t}$. For simplicity, we assume all equity financing.

Summing together assets-in-place and the growth option gives a young firm's total equity value:

$$
V_{Y, s_{t}}=V_{Y, s_{t}, t}=\xi_{Y} A_{t}+G_{s_{t}}
$$

After exercise, $t>\tau$, the young firm is mature and so the growth option value is merely the value of the additional assets in place and is no longer dependent on the volatility regime, $G_{t}=\xi A_{t}$, and so $V_{Y, t}=\xi_{Y} A_{t}+\xi A_{t}=\xi_{M} A_{t}$.

The dependence of the growth option value on the idiosyncratic volatility regime comes from our assumption that idiosyncratic volatility is stochastic. It is the convexity of the option value with respect to $P_{t}$ that ensures the optimal decision to expand and hence young firm value depend on the volatility regime $s_{t}$ (Guo, Miao, and Morelled (2005)).

The random stopping time, $\tau$, is chosen to maximize firm value and is defined by the optimal investment thresholds $P_{L}^{*}, P_{H}^{*}$, which are determined by smooth pasting conditions (see Guo, Miao, and Morelled (200.5)). In the low idiosyncratic volatility state, the growth option is worth less, making it optimal to exercise the option earlier: $P_{L}^{*}<P_{H}^{*}$. When a firm is in the low state exercise occurs as soon as the price process hits the threshold $P_{L}^{*}$ from below. In the high state, exercise occurs if the price process hits the threshold $P_{H}^{*}$ from below or, if $P_{t} \geq P_{L}^{*}$, as soon as the volatility state switches to low, whichever comes first. As a consequence, investment can occur instantaneously, without a change in the level of the price, purely because of a fall in idiosyncratic volatility.

The following proposition gives the value of the growth option for a young firm.

Proposition 1 In its low idiosyncratic volatility regime, a young firm's growth option value is given by

$$
G_{L, t}=\left\{\begin{array}{cc}
\frac{1}{l_{1}-l_{2}}\left[\delta_{L}\left(l_{2}\right)\left(\frac{P_{t}}{P_{L}^{*}}\right)^{l_{1}}-\delta_{L}\left(l_{1}\right)\left(\frac{P_{t}}{P_{L}^{*}}\right)^{l_{2}}\right], & P_{t}^{\max }<P_{L}^{*} \\
\xi A\left(P_{t}\right)-I, & P_{t}^{\max }=P_{L}^{*} \\
\xi A\left(P_{t}\right), & P_{t}^{\max }>P_{L}^{*}
\end{array}\right.
$$


where $P_{t}^{\max }=\sup _{t \geq 0}\left\{P_{u}: u \in[0, t)\right\}$ is the firm's maximum output price,

$$
\delta_{L}(l)=\frac{\xi P_{L}^{*}}{r-\hat{\mu}}-l \xi A\left(P_{L}^{*}\right)
$$

and $l_{2}>l_{1}>0$ are the positive roots of the quartic

$$
q_{L}(l) q_{H}(l)-\lambda_{L} \lambda_{H}=0
$$

where

$$
\begin{aligned}
& q_{L}(l)=\frac{1}{2}\left[\left(\sigma_{L}^{i d}\right)^{2}+\left(\sigma^{s y s}\right)^{2}\right] l(l-1)+\hat{\mu} l-\left(r+\lambda_{H}\right), \\
& q_{H}(l)=\frac{1}{2}\left[\left(\sigma_{H}^{i d}\right)^{2}+\left(\sigma^{s y s}\right)^{2}\right] l(l-1)+\hat{\mu} l-\left(r+\lambda_{L}\right) .
\end{aligned}
$$

In its high idiosyncratic volatility regime, a young firm's growth option value is given by

$$
G_{H, t}=\left\{\begin{array}{cc}
\frac{1}{l_{1}-l_{2}}\left[\epsilon\left(l_{1}\right) \delta_{L}\left(l_{2}\right)\left(\frac{P_{t}}{P_{L}^{*}}\right)^{l_{1}}-\epsilon\left(l_{2}\right) \delta_{L}\left(l_{1}\right)\left(\frac{P_{t}}{P_{L}^{*}}\right)^{l_{2}}\right], & P_{t}<P_{L}^{*}, P_{t}^{\max }<P_{H}^{*} \\
\frac{\lambda_{L}}{r+\lambda_{L}}\left(\xi A\left(P_{t}\right)-I\right)+\frac{1}{j_{1}-j_{2}}\left\{\delta_{H}\left(j_{2}\right)\left(\frac{P_{t}}{P_{H}^{*}}\right)^{j_{1}}-\delta_{H}\left(j_{1}\right)\left(\frac{P_{t}}{P_{H}^{*}}\right)^{j_{2}}\right], & P_{t} \in\left[P_{L}^{*}, P_{H}^{*}\right), P_{t}^{\max }<P_{H}^{*} \\
\xi A\left(P_{t}\right)-I, & P_{t}^{\max }=P_{H}^{*} \\
\xi A\left(P_{t}\right), & P_{t}^{\max }>P_{H}^{*}
\end{array}\right.
$$

where

$$
\begin{aligned}
\epsilon(l) & =-\frac{\lambda_{L}}{q_{H}(l)}, \\
\delta_{H}(j) & =\xi P_{H}^{*}\left(\frac{1}{r-\hat{\mu}}-\frac{\lambda_{L}}{r+\lambda_{L}}\right)-j \frac{r}{r+\lambda_{L}}\left(\xi A\left(P_{H}^{*}\right)-I\right),
\end{aligned}
$$

and $j_{1}>j_{2}$ are the roots of the quadratic

$$
q_{H}(j)=0
$$

The optimal investment thresholds $P_{i}^{*}, i \in\{L, H\}$ are given by the following system of non- 
linear algebraic equations.

$$
\begin{aligned}
& \frac{1}{l_{1}-l_{2}}\left[\epsilon\left(l_{1}\right) \delta_{L}\left(l_{2}\right)-\epsilon\left(l_{2}\right) \delta_{L}\left(l_{1}\right)\right]-\frac{1}{j_{1}-j_{2}}\left[\delta_{H}\left(j_{2}\right)\left(\frac{P_{L}^{*}}{P_{H}^{*}}\right)^{j_{1}}-\delta_{H}\left(j_{1}\right)\left(\frac{P_{L}^{*}}{P_{H}^{*}}\right)^{j_{2}}\right]-\frac{\lambda_{L}}{r+\lambda_{L}}\left(\xi A\left(P_{L}^{*}\right)-I\right)=0 \\
& \frac{1}{l_{1}-l_{2}}\left[l_{1} \epsilon\left(l_{1}\right) \delta_{L}\left(l_{2}\right)-l_{2} \epsilon\left(l_{2}\right) \delta_{L}\left(l_{1}\right)\right]-\frac{1}{j_{1}-j_{2}}\left[j_{1} \delta_{H}\left(j_{2}\right)\left(\frac{P_{L}^{*}}{P_{H}^{*}}\right)^{j_{1}}-j_{2} \delta_{H}\left(j_{1}\right)\left(\frac{P_{L}^{*}}{P_{H}^{*}}\right)^{j_{2}}\right]-\frac{\lambda_{L}}{r+\lambda_{L}} \frac{\xi P_{H}^{*}}{r-\hat{\mu}}=0 .
\end{aligned}
$$

Importantly, the proposition reveals that the value of a young firm's growth option value jumps upward when idiosyncratic volatility shifts up, in stark contrast to assets-in-place, which are independent of idiosyncratic volatility. Therefore, the dependence of a young firm's value on its idiosyncratic volatility regime is attributed entirely to the growth option.

\section{Insert Figure $⿴$ here}

Figure $\mathbb{\square}$ provides a graphical illustration of Proposition 1 for different sets of parameter values for $\sigma_{H}^{i d}$ and $\sigma_{L}^{i d}$. Comparing the graphs across panels reveals that the opportunity to expand has a larger valuation in the high regime than in the low regime, and the difference is increasing in the spread between $\sigma_{H}^{i d}$ and $\sigma_{L}^{i d}$. The last panel reveals that the model results in a single valuation profile if $\sigma_{H}^{i d}=\sigma_{L}^{i d}$, which is the usual specification in standard growth option models.

\subsection{Returns}

For mature firms, expected returns differ in the cross-section based solely on variation in output prices - idiosyncratic volatility is irrelevant. In contrast, for young firms, variation in idiosyncratic volatility across firms impacts the cross-section of returns via growth options. In particular, returns on the growth option possessed by a young firm satisfy the two key properties described in Section $\rrbracket$, making it possible to resolve the positive and negative $I V$ ol-return relations.

We start by analyzing returns for a mature firm. First observe that because the value of a mature firm exhibits constant returns with respect to production scale, the return on a mature firm is independent of the production scale. Consequently, the return on a young firm's assets- 
in-place is the same as the return on a mature firm, if their output prices are equal. It therefore makes more sense to refer to the return on assets-in-place, which we denote by $d R_{A, t}$ and is given by

$$
d R_{A, t}=\left[r+\left(1+L\left(P_{t}\right)\right) \Theta \sigma^{s y s}\right] d t+\left(1+L\left(P_{t}\right)\right) \sigma^{s y s} d B_{t}^{s y s}+\left(1+L\left(P_{t}\right)\right) \sigma_{t}^{i d} d B_{t}^{i d}
$$

where $L\left(P_{t}\right)=\frac{\frac{c}{r}}{\frac{P_{t}}{r-\hat{\mu}}-\frac{c}{r}}$.

The return on assets-in-place satisfies neither of the two properties which lead to the resolution of the positive and negative $I V o l$-return relations: unexpected changes in idiosyncratic volatility are driven by a Markov chain which is independent of the idiosyncratic shock, $d B_{t}^{i d}$ and systematic volatility, $\left(1+L\left(P_{t}\right)\right) \sigma^{\text {sys }}$, is independent of idiosyncratic volatility.

We now look at the returns of a young firm, where stochastic idiosyncratic volatility plays a prominent role. The return on a young firm, $d R_{Y, s_{t}}$, is the weighted average of the return on its assets-in-place and growth option, i.e.

$$
d R_{Y, s_{t}}=\left(1-\frac{G_{s_{t}}}{V_{Y, s_{t}}}\right) d R_{A, t}+\frac{G_{s_{t}}}{V_{Y, s_{t}}} d G_{s_{t}}
$$

where $d G_{s_{t}}$ is the return on the firm's growth option.

We already know that the return on assets-in-place will not help us resolve IVol-return relations, so we focus on the growth option return. Before proceeding, we observe that if a firm's idiosyncratic volatility changes at date- $t$, we denote the idiosyncratic volatility state just before the change by $s_{t-}$ and just after by $s_{t}$. The following proposition gives the return on a young firm's growth option.

Proposition 2 The growth option return is given by

$$
\begin{aligned}
\frac{d G_{s_{t-}}}{G_{s_{t-}}} & =\mu_{G, s_{t-}} d t \\
& +\Omega_{s_{t-}}\left(\sigma^{s y s} d B_{t}^{s y s}+\sigma_{s_{t-}}^{i d} d B_{t}^{i d}\right)+\frac{G_{s_{t}}-G_{s_{t-}}}{G_{s_{t-}}} d M_{s_{t-} s_{t}, t}^{i d}
\end{aligned}
$$

where

$$
\mu_{G, s_{t-}}=\Omega_{s_{t-}} \mu+\frac{G_{s_{t}}-G_{s_{t-}}}{G_{s_{t-}}} \lambda_{s_{t}}+\frac{1}{2} \frac{P_{t}^{2}}{G_{s_{t-}}} \frac{\partial^{2} G_{s_{t-}}}{\partial P_{t}^{2}}\left(\left(\sigma^{s y s}\right)^{2}+\left(\sigma_{s_{t-}}^{i d}\right)^{2}\right)
$$


and

$$
\Omega_{s_{t-}}=\frac{P_{t}}{G_{s_{t-}}} \frac{\partial G_{s_{t-}}}{\partial P_{t}}
$$

is the elasticity of the growth option with respect to the output price,

$$
d M_{s_{t-} s_{t}, t}^{i d}=d N_{s_{t-} s_{t}, t}^{i d}-\lambda_{s_{t}} d t
$$

is a compensated Poisson process and hence discontinuous martingale, driven by changes in the young firm's idiosyncratic volatility regime, i.e.

$$
d N_{s_{t-} s_{t}, t}^{i d}=\left\{\begin{array}{ll}
0 & , s_{t}=s_{t-} \\
1 & , s_{t} \neq s_{t-}
\end{array} .\right.
$$

In the no action region, $P_{t}^{\max }<P_{L}^{*}$, the growth option's elasticity with respect to the output price is lower when idiosyncratic volatility is high, i.e. $\Omega_{L}>\Omega_{H}$, but the growth option's idiosyncratic volatility is higher when idiosyncratic volatility is high, i.e. $\sigma_{L}^{i d} \Omega_{L}<\sigma_{H}^{i d} \Omega_{H}$, and the growth option's expected return when there is no change in idiosyncratic volatility is higher when idiosyncratic volatility is high, i.e. $\mu_{G, H}-\frac{G_{L}-G_{H}}{G_{H}} \lambda_{L}>\mu_{G, L}-\frac{G_{H}-G_{L}}{G_{L}} \lambda_{H}$.

Since the increment in the idiosyncratic risk factor, $d M_{s_{t-} s_{t}, t}^{i d}$ also drives changes in idiosyncratic volatility, Property 1 holds for the growth option's return. The return on assets-in-place is independent of the firm's idiosyncratic volatility regime, so it follows that Property 1 also holds for a young firm's return.

As idiosyncratic volatility rises, the growth option's elasticity, $\Omega$, falls and so the option's systematic volatility decreases. Hence, Property 2 is satisfied for the growth option's return. However, the young firm's value is the sum of assets-in-place and its growth option, so it does not immediately follow that the young firm's systematic volatility is lower in the high idiosyncratic volatility regime - we need to account for the effect of a change in the weight, $\frac{G_{s_{t}}}{V_{Y, s_{t}}}$, in the young firm's return as shown in Equation ([.2.2). The following proposition establishes that the young firm's systematic volatility is lower in the high idiosyncratic volatility regime. 
Proposition 3 A young firm's conditional systematic return volatility is given by

$$
\sigma_{R_{Y}, s_{t}}^{\text {sys }}=\left[\left(1-\frac{G_{s_{t}}}{V_{Y, s_{t}}}\right)\left(1+L\left(P_{t}\right)\right)+\frac{G_{s_{t}}}{V_{Y, s_{t}}} \Omega_{s_{t}}\right] \sigma^{\text {sys }}
$$

and is lower in the high idiosyncratic volatility regime, i.e.

$$
\sigma_{R_{Y}, H}^{s y s}<\sigma_{R_{Y}, L}^{s y s}
$$

Propositions $\boldsymbol{\square}$ and $\mathbf{\square}$ together show that a young firm's return endogenously satisfies Properties 1 and 2.

We now discuss the implications of the properties of growth option returns for $I V$ ol-return relations in more detail. From (B.22) and (B.2.3), we can see that abnormal returns for a young firm are given by

$$
\begin{aligned}
d R_{Y, s_{t-}}^{a} & =d R_{Y, s_{t-}}-E_{t}\left[d R_{Y, s_{t-}} \mid s_{t-}\right] \\
& =\left[\left(1-\frac{G_{s_{t-}}}{V_{Y, s_{t-}}}\right)\left(1+L\left(P_{t}\right)\right)+\frac{G_{s_{t-}}}{V_{Y, s_{t-}}} \Omega_{s_{t-}}\right]\left(\sigma^{s y s} d B_{t}^{s y s}+\sigma_{s_{t-}}^{i d} d B_{t}^{i d}\right)+\frac{G_{s_{t}}-G_{s_{t-}}}{V_{Y, s_{t-}}} d M_{s_{t-}}^{i d} s_{t}, t
\end{aligned}
$$

Furthermore, changes in idiosyncratic volatility can be written as

$$
d \sigma_{s_{t-}}^{i d}=\lambda_{s_{t}}\left(\sigma_{s_{t}}^{i d}-\sigma_{s_{t-}}^{i d}\right) d t+\left(\sigma_{s_{t}}^{i d}-\sigma_{s_{t-}}^{i d}\right) d M_{s_{t-} s_{t}, t}^{i d}
$$

There is one common risk factor driving changes in abnormal returns and idiosyncratic volatility, i.e. $d M_{s_{t-} s_{t}, t}^{i d}$. Since growth option value is higher when idiosyncratic volatility is higher, the change in idiosyncratic volatility, $\sigma_{s_{t}}^{i d}-\sigma_{s_{t-}}^{i d}$ and the change in growth option value $G_{s_{t}}-G_{s_{t-}}$ have the same sign. Property 1 therefore holds and so a young firm's abnormal returns will be positively correlated with changes in its idiosyncratic volatility, contributing to the positive $I V o l$ -

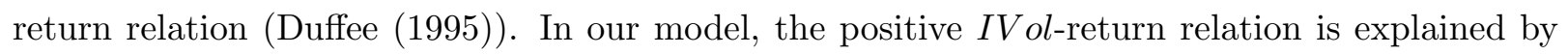
the jumps in returns of young firms when they experience a switch in their idiosyncratic operating risk.

Proposition [ ] shows that a young firm's systematic volatility is higher when idiosyncratic 
volatility is low, i.e. Property 2 holds. The intuition follows from standard option pricing results - when volatility increases the value of an option increases, but the option also becomes less sensitive to changes in the underlying, i.e. the option delta falls. In the context of our model, the growth option delta and hence its elasticity with respect to output price is lower when idiosyncratic volatility is higher. This drives down the systematic volatility of the growth option and hence young firm returns in the high idiosyncratic volatility state. Applying the basic asset pricing equation to the returns of a young firm, $d R_{Y, s_{t-}}$, we obtain

$$
E_{t}\left[d R_{Y, t} \mid s_{t-}\right]=\left(r+\sigma_{R, s_{t-}}^{s y s} \Theta\right) d t
$$

Therefore, expected returns will be lower when idiosyncratic volatility is high. ${ }^{12}$ Observe that in portfolio-based tests, sorting firms by end-of-month realized IVol is akin to sorting by the firms' most recent idiosyncratic volatility regime. If real options and stochastic idiosyncratic risk are incorporated into firm valuations, our model implies that, holding other factors constant, return realizations of $I V o l$ portfolios should reflect differences in expected returns, thereby creating a negative correspondence between future equity returns and current idiosyncratic risk (Ang, Hodrick, Xing, and Zhang ([2006)). In summary, our model generates reversals in equity returns correlating positively with contemporaneous changes in $I V o l$ and inversely with past realized $I V o l$, generating the positive and the negative $I V o l$-return relations. We explore this feature of the model in the sequel with numerical simulations and empirical tests.

Lastly, our model offers the basis for a novel prediction on the relation between stock returns and idiosyncratic return volatility. Proposition $\nabla$ shows that a growth option's expected return contains a continuous component, i.e.

$$
\mu_{G, s_{t-}}^{c}=\Omega_{s_{t-}} \mu+\frac{1}{2} \frac{P_{t}^{2}}{G_{s_{t-}}} \frac{\partial^{2} G_{s_{t-}}}{\partial P_{t}^{2}}\left(\left(\sigma^{s y s}\right)^{2}+\left(\sigma_{s_{t-}}^{i d}\right)^{2}\right)
$$

plus a probability weighted jump term

$$
\frac{G_{s_{t}}-G_{s_{t-}}}{G_{s_{t-}}} \lambda_{s_{t}}
$$

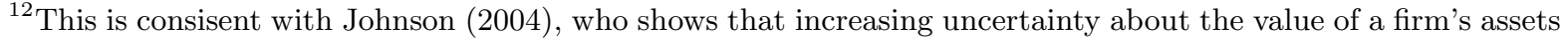
while holding the risk premium constant lowers the expected returns of levered firms.
} 
Proposition $\nabla$ states that the continuous component of the expected return is positively correlated with the idiosyncratic volatility regime. Hence, our model implies that stock returns should correlate positively with $I V$ ol during times between large changes in $I V o l$. We test this novel empirical prediction in the sequel. ${ }^{13}$

\section{Insert Figure 2 here}

Figure 2 provides a graphical illustration of the ideas conveyed in Proposition 7 for different sets of parameter values for $\sigma_{H}^{i d}$ and $\sigma_{L}^{i d}$. Panel (a) shows that there is a negative difference in systematic volatility $\left(\Omega_{H}-\Omega_{L}\right) \sigma^{\text {sys }}$, while Panels (b) and (c) show that there is a positive difference in total volatility from diffusion risk, $\Omega_{H} \sqrt{\left(\sigma^{\text {sys }}\right)^{2}+\left(\sigma_{H}^{i d}\right)^{2}}-\Omega_{L} \sqrt{\left(\sigma^{\text {sys }}\right)^{2}+\left(\sigma_{L}^{i d}\right)^{2}}$, and the continuous drift terms $\mu_{G, H}^{c}-\mu_{G, L}^{c}$ between regimes. Panel (d) of the figure shows that there is a negative difference in jump terms $\frac{G_{L}-G_{H}}{G_{H}}-\frac{G_{H}-G_{L}}{G_{L}}$. All the differences are increasing in the spread between $\sigma_{H}^{i d}$ and $\sigma_{L}^{i d}$, suggesting that the relation between returns and idiosyncratic volatility should be stronger the greater the variation in the firms' operating risk. Lastly, the differences in all quantities are identically zero if the volatility values are the same in both regimes, which is the usual specification in standard growth option models.

\section{Simulations}

In this section, we verify that our model is able to simultaneously produce the positive and the negative $I V o l$-return relations by using data simulated from the model itself to carry out the main analysis in Duffed (एप.95) and Ang et al. (एण06).

Using the analytical solutions of the model, we simulate a large panel of daily firm values by first simulating a single path of $B_{t}^{s y s}$. Then we simulate 2,500 separate paths of $P_{t}$ and idiosyncratic volatility values using the stochastic processes defined in (B.2). ${ }^{14}, 15$ Each simulated

\footnotetext{
${ }^{13}$ Consider a firm that experiences an increase in idiosyncratic operating risk. Pre-jump the firm experiences relatively low returns driven by the nonmaterialized potential for positive jump in idiosyncratic volatility; and similarly, the firm experiences relatively high post-jump returns driven by nonmaterialized negative jumps in idiosyncratic volatility. Hence, if real options and stochastic idiosyncratic risk are incorporated into firm valuations, stock returns should correlate positively with $I \mathrm{Vol}$ in intervals between large changes in $I \mathrm{Vol}$.

${ }^{14}$ This is to be consistent with the data sample in our empirical study which contains an average of 2,412 firms each month with non-missing sales growth observations after applying our filters.

${ }^{15} \mathrm{Hanson}(\mathrm{\square UV})$ is a good reference for numerical simulations of diffusion and Poisson processes.
} 
path of $P_{t}$ corresponds to the output price series for a single firm. The time horizon is 50 years with 20 trading days in each month, corresponding to a total of 12,000 daily observations for each firm. Then, for each day and each firm, we compute firm values using equations (B.]), (B.]), (B.]), and (B.J)

Initial maturities are drawn from a uniform distribution with equal probabilities of young and mature firms, which are updated daily. To ensure mature firms do not dominate the sample over time, mature firms exit the sample upon the arrival of an independent Poisson event with intensity $\lambda_{\text {exit }}=0.01$ per unit time or if the firm value reaches zero due to low realizations of $P_{t}$ values. Exiting firms are replaced by new young entrants. ${ }^{16}$

We compute daily abnormal returns relative to the $C A P M$ based on $C A P M$ beta expressions for assets-in-place and the growth option. Then for each firm and each month, we compute IVol as the standard deviation of the abnormal returns. The beta of a young firm is computed as a weighted average of the beta of the firm's assets-in-place and the beta of the firm's growth option where the weights are based on the proportion of firm value in the growth option.

We use the simulated returns to carry out the main analysis in Duffed (एप9.5) and Ang et al. (एवण6) and store the results. Then, we repeat the entire process 99 more times in order to arrive at a set of 100 estimates allowing us to carry out t-tests in order to investigate the statistical significance of the results. To investigate the model's reliance on stochastic idiosyncratic risk, the simulation steps described thus far are repeated using three different sets of values for $\sigma_{H}^{i d}$ and $\sigma_{L}^{i d}$. Table $\square$ summarizes the set of parameters used to solve the model.

\section{Insert Table 田 here}

Using the baseline set of model parameters, Figure $\mathbf{3}$ shows the month-end values of a single simulated path of $P$, the corresponding firm values, idiosyncratic volatility regimes, realized idiosyncratic return volatilities $I V o l$ and realized returns. Panels (a) and (b) reveals that firm value, $V_{s_{t}}$, follows a similar pattern to $P$, as expected. Panels (c) to (d) show that returns and IVol appear to be regime dependent, consistent with Proposition 2.

\footnotetext{
${ }^{16}$ We assume random entry and exit in our simulations for ease of implementation. An earlier version of our paper which included endogenous entry and exit decisions by firms in a competitive product market equilibrium model produced similar asset pricing results.
} 


\section{Insert Figure 3 here}

\subsection{The Positive Return-Volatility Relation}

Using the simulated data, we fit Eama and MacBeth (ए.973) monthly cross-sectional regressions of $\log$ return $r_{t}$ on $\Delta I V o l_{t}$ in order to investigate if the model can create the positive $I V$ ol-return relation. The cross sectional regression model for month $t$ is

$$
r_{t}=\gamma_{0, t} \iota+\gamma_{1, t} \Delta I V o l_{t}+\eta_{t}
$$

where $\iota$ is a vector of ones, $r_{t}$ is a vector of $r_{j, t}$ and $\Delta I V o l_{t}$ is a vector of $\Delta I V o l_{j, t}$ of all the firms $j \in J$.

\section{Insert Table 2 here}

Table 1 reports the results. The table shows that if $\sigma_{H}^{i d}>\sigma_{L}^{i d}$ the model is able to produce the positive $I V$ ol-return relation which is more pronounced for larger spreads between $\sigma_{H}^{i d}$ and $\sigma_{L}^{i d}$, but negligible and insignificant if $\sigma_{H}^{i d}=\sigma_{L}^{i d}$. This confirms that the stochastic nature of idiosyncratic risk is crucial to generate the positive $I V$ ol-return relation.

\subsection{The Negative Return-Volatility Relation}

Using the simulated data, we form portfolios based on $I V o l$ in order to investigate if the model can create the negative $I V o l$-return relation. At the end of each month, we sort firms by $I V o l$ into five equally sized groups. Then, we compute value-weighted one-month portfolio returns for each of the five groups. The portfolios are rebalanced at the end of each month.

\section{Insert Table 3 here}

Table $\mathbf{1}$ reports the results. IVol-sorted portfolios are reported across columns. The zero-cost (high minus low) $I V o l$ portfolios are reported in the last column. Figure $\mathbb{\theta}$ provides a visual illustration of the average returns reported in the table. The zero-cost IVol portfolio has a highly significant and negative average return if $\sigma_{H}^{i d}>\sigma_{L}^{i d}$, with more amplified results for larger spreads 
between $\sigma_{H}^{i d}$ and $\sigma_{L}^{i d}$. The model offers negligible and insignificant results if $\sigma_{H}^{i d}=\sigma_{L}^{i d}$, confirming that the stochastic nature of idiosyncratic risk is crucial to generate the negative $I V$ ol-return relation.

\section{Insert Figure 团 here}

We conduct further analysis by fitting Eama_and MacBeth (ए.973) monthly cross-sectional regressions of returns on lagged $I V o l$. The regression model for month $t$ is

$$
r=\gamma_{0, t} \iota+\gamma_{1, t} I V o l_{t-1}+\eta_{t}
$$

Table $\nabla$ reports the results. There is a negative and highly statistically significant return-lag IVol relation if $\sigma_{H}^{i d}>\sigma_{L}^{i d}$ with more amplified results for larger spreads between $\sigma_{H}^{i d}$ and $\sigma_{L}^{i d}$, but negligible and insignificant result if $\sigma_{H}^{i d}=\sigma_{L}^{i d}$. These results reaffirm the earlier portfolio results.

Taken together, the simulations confirm the prediction that real options and stochastic idiosyncratic operating risk play a significant role in generating the two $I V$ ol-return relations.

\section{$5 \quad$ Empirical Analysis}

In this section, we test the novel empirical predictions of our model. This is in contrast with the previous section, where we showed that the positive and negative $I V$ ol-return relations are present in simulated data from our model.

\subsection{Data, Variable Descriptions and Summary Statistics}

Daily and monthly stock returns are from CRSP. Daily and monthly factor returns and risk-free rates are from Ken French's website. ${ }^{17}$ All accounting variables are from annual COMPUSTAT files. Our sample period is from January, 1971 to December, 2010 for all market-based variables. ${ }^{18}$ We consider only ordinary shares traded on the NYSE, AMEX and Nasdaq with primary link to companies on COMPUSTAT with US data source. We eliminate utility (SIC codes between 4900 and 4999) and financial companies (SIC codes between 6000 and 6999), companies with less

\footnotetext{
${ }^{17}$ http:// mba.tuck.dartmouth.edu/ pages/faculty/ken.french/data library.html

${ }^{18}$ The annual number of firms on COMPUSTAT with non-missing sales and net income observations is relatively low prior to the 70's after applying the reported filters.
} 
than one year of accounting data, stock price of zero and negative book equity values. In order to remove the effects of delisting, we eliminate return observations within one year of delisting if the delisting code has the first digit different from 1 . The final sample size is over 1 million monthly observations with non-missing return and idiosyncratic return volatility values.

\subsubsection{Idiosyncratic Volatility}

Our empirical study requires a measure for the firms' idiosyncratic operating risk. Stock return volatility is commonly used as a proxy for the volatility of the firms' operations (Leahy and Whited (एप96); Bulan (2005); Grullon, Lyandres, and Zhdanov (एण0)). Following Ang, Hodrick, Xing, and Zhang (2006), for each firm $j$ and month $t$, we estimate idiosyncratic return volatility $I V o l$ as the standard deviation of the daily stock returns relative to the Fama and French 3 factor model:

$$
r_{j, \tau}=\alpha_{i}+\beta_{j, M K T} M K T_{\tau}+\beta_{j, S M B} S M B_{\tau}+\beta_{j, H M L} H M L_{\tau}+\varepsilon_{j, \tau}
$$

where $I V \operatorname{Vol}_{j, t}=\sqrt{\operatorname{var}\left(\log \left(1+\varepsilon_{j, \tau}\right)\right)}$ and $\varepsilon_{j, \tau}$ for $\tau \in(t-1, t]$ are the residuals from fitting regression (15). ${ }^{19}$ Furthermore, we define $\Delta I V o l_{j, t}$ as the change in $I V o l$ from previous month, i.e., $I V o l_{j, t}-I V o l_{j, t-1}$.

We also require an empirical proxy to capture the variability in the idiosyncratic risk of the firms. Towards this end, for each firm, we consider the stock's 70th and 30th percentile values of IVol to be the thresholds that define the volatility regimes for the firm, and we denote the spread $\overline{\Delta I \mathrm{Vol}_{j}}$ to be to be the difference between the 70 th and 30 th percentile values.

\subsubsection{Firm Characteristics}

We require several variables shown in the literature to be determinants of stock returns as controls when conducting cross-sectional return regressions. They are: log market equity; log book-tomarket; past stock returns; CAPM beta; and trading volume. ${ }^{20}$

\footnotetext{
${ }^{19}$ Following Grullon, Lyandres, and Zhdanov (एण⿰丿) , we use the logarithm of the residuals in order to mitigate

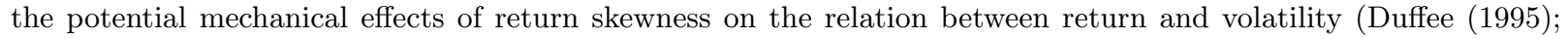
Chen, Hong, and Stein (एण्ण); Kapadia (एण⿰)) ).

${ }^{20}$ Following Eama_and French ([1.93), market value of equity is defined as the share price at the end of June times the number of shares outstanding. Book equity is stockholders' equity minus preferred stock plus balance sheet deferred taxes and investment tax credit if available, minus post-retirement benefit asset if available. If missing, stockholders' equity is defined as common equity plus preferred stock par value. If these variables are missing, we use book assets less liabilities. Preferred stock, in order of availability, is preferred stock liquidating value, or
} 


\subsubsection{Real Option Proxies}

We also require empirical proxies for the extent that firms incorporate real options. We follow Grullon, Lyandres, and Zhdanov (णㅣ) in the selection of our main growth option variables, and additionally, create some of our own.

The most common type of real options come in the form of future growth opportunities

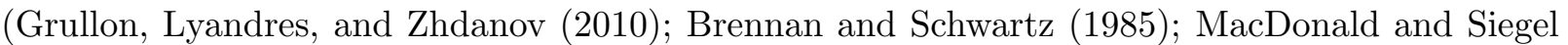
(एप86); Majd and Pindyck (एप87); Pindyck (एप88)). We consider firm size and firm age as inverse measures of growth opportunities because larger and older firms tend to be more mature and have larger proportions of their values from assets-in-place, while smaller and younger firms tend to derive value from future growth opportunities (Brown and Kapadia (2007); Carlson, Fisher, and

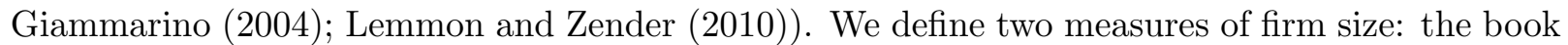
value of total assets and the market value of equity. Age is defined as the difference between the month of the return observation and the month in which the stock first appeared on CRSP.

Growth opportunities are revealed in growth capitalized in the future in the form of increased sales, profits or investments. Therefore, for our third set of growth variables, we define future sales growth as the sum of the sales growth rates starting 2 years and ending 5 years after the stock return observation. Future profit and future investment growth are defined similarly. ${ }^{21}$

The IVol-return relations arise endogenously in our model insofar as equity valuations incorporate idiosyncratic operating risk and convexities with respect to cashflows. We consider a novel proxy for real option intensity to capture convexity in firm valuation. The equity of a firm is

preferred stock redemption value, or preferred stock par value. The denominator of the book-to-market ratio is the December closing stock price times the number of shares outstanding. We match returns from January to June of year $t$ with COMPUSTAT-based variables of year $t-2$, while the returns from July until December are matched with COMPUSTAT variables of year $t-1$. This matching scheme is conservative and ensures that the accounting information-based observables are contained in the information set prior to the realization of the market-based variables. We employ the same matching scheme in all our matches involving accounting related variables and CRSP-based variables. We define past returns as the buy-and-hold gross compound returns minus 1 during the six-month period starting from month $t-7$ and ending in month $t-2$. Following Karpoft (एप87), trading volume is trading volume normalized by the number of shares outstanding during month $t$. Lastly, stock CAPM beta is the estimated coefficient from rolling regressions of monthly stock excess returns on the market factor's excess returns. We use a 60-month window every month requiring at least 24 monthly return observations in a given window, and use the procedure suggested in Dimson (एप7प) with a lag of one month in order to remove biases from thin trading in the estimations.

${ }^{21}$ One caveat with these growth variables is the possibility of look-ahead bias. Following Grullon, Lyandres, and Zhdanov (स्त) , we are not concerned with potential issues related to look-ahead bias since the focus of our paper is on investigating the relation between return and volatility, and not on predicting future stock returns. Also, we alleviate concerns of spurious correlation between contemporaneous surprises in growth and monthly returns by merging month $t$ returns with growth variables starting two years following the return observation. 
akin to a call option on the firm's assets with the strike price amounting to the total value of the

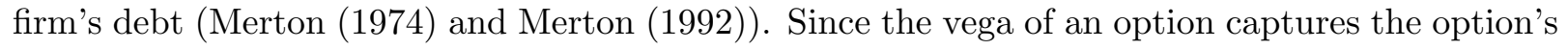
sensitivity to the volatility of the underlying asset, the relation between $I V o l$ and stock returns should be stronger for firms with higher equity vegas. To test this hypothesis, for each firm $j$ and year $n$, we utilize the firms' capital structure and the Black and Scholes' formula to define the firms' equity vega as follows:

$$
\operatorname{vega}_{j, n}=V_{j, n} N^{\prime}\left(d_{j, n}\right) \sqrt{5}
$$

where $d_{j, n}=\frac{\ln \left(\frac{V_{j, n}}{D_{j, n}}\right)+\left(r_{f, n}-\frac{\sigma_{j, n}^{2}}{2} \times 5\right)}{\sigma_{j, n} \sqrt{5}}, N^{\prime}(x)=\frac{\exp \left(-x^{2} / 2\right)}{\sqrt{2 \pi}}, r_{f, n}$ is the annualized risk free rate, $\sigma_{j, n}$ denotes firm $j$ 's annualized six-month rolling window idiosyncratic volatility based on the Fama French 3 factor model, $V_{j, n}$ denotes the sum of the firm's market equity value and book value of debt, and $D_{j, n}$ is the firm's book value of debt. For simplicity, we assume that firms have a debt maturity of 5 years. Option vegas are relatively invariant over most of the range of possible values for the underlying asset. ${ }^{22}$ Therefore, we also classify firms based on equity vega values in relation to the other firms in the sample. To this end, we categorize high vega firms as firms with vegas in the top tercile based on breakpoint values found among NYSE firms in the sample.

We expand the set of proxies for option intensity described thus far by classifying firms as small, young, high sale growth, high investment growth and high profit growth if the corresponding option intensity proxies have values that fall in top or bottom tercile values based on breakpoint values found among NYSE firms in the sample.

Lastly, it is natural to think that firms in certain industries possess more growth options than others, and real option intensity may be captured by the firms' industry membership. Following Grullon, Lyandres, and Zhdanov (2010), we consider three main classifications of industries based on the 49 industries of Eama and French ([प97). We define firms with membership in Fama and French (FF) industries 27 (precious metals), 28 (mining), and 30 (oil and natural gas) as natural resource firms. We classify firms in FF industries 22 (electrical equipment), 32 (telecommunications), 35 (computers), 36 (computer software), 37 (electronic equipment), and 38 (measuring and control equipment) as high-tech firms. Membership in FF industries 12 (medical equipment) and

\footnotetext{
${ }^{22}$ A call option's vega is greatest when the option is at the money, and relatively low and invariant over the remainder of possible prices for the underlying stock (see 배미미) ).
} 
13 (pharmaceutical products) are defined as biotechnology or pharmaceutical firms. Firms with membership in any one of these three industry classifications are defined as all-growth industry firms.

\subsubsection{Summary Statitics}

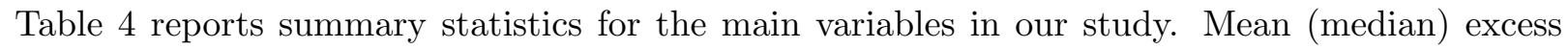
return in our sample is $0.9976 \%(-0.41 \%)$ per month or about $11.9712 \%(-4.92 \%)$ per year. Mean (median) daily idiosyncratic stock return volatility $I V$ ol is $2.9476 \%(2.2782 \%)$ or about $44.0171 \%$ (34.0208\%) annually. Our IVol estimates are similar to those reported in Ang, Hodrick, Xing, and Zhang (एण06) and Grullon, Lyandres, and Zhdanov (200). Mean (median) month-to-month change in $I V$ ol is $-.0023 \%(-0.011 \%)$. The standard deviation is $2.1096 \%$ and similar to the value reported in Grullon, Lyandres, and Zhdanov (खण) ).

\section{Insert Table $⿴$ here}

\subsection{The Switch Effect}

To the extent that real options and stochastic idiosyncratic risk are incorporated into firm values, the model predicts that stock returns should correlate positively with $I V$ ol during intervals between large changes in $I V o l$ (the switch effect hereafter) reflecting the dependence of the options' returns on the volatility regime. Post-switch returns should be greater than pre-switch returns for stocks that experience up switches in $I V o l$, and lower for stocks that experience down switches in IVol.

We use event studies methodology to verify this prediction. To this end, for each firm $j$ and month $t$, we define an up switch in $I V o l$ if $I V o l_{j, t-1}$ was below the firm's 30 th percentile value and if $I V$ ol $_{j, t}$ exceeds the firm's 70th percentile value, capturing the notion of an up switch in idiosyncratic volatility. A down switch event is defined similarly. Once all the up and down switch events are identified for each stock and each month in our sample, we compute the 5-month average return ending in the month prior to the month of the event, and the 5-month average

returns beginning from the month after the event. Then we investigate how the difference in average returns around switch months relate to option intensity. More specifically, we risk-adjust 
monthly returns according to the Eama and French (एप9.3) 3-factor model

$$
r_{j, t}^{*}=r_{j, t}-r_{f, t}-\sum_{k=1}^{3} \widehat{\beta_{j, k}} F_{k, t}
$$

where $r_{j, t}$ is the return on stock $j$ in month $t, r_{f, t}$ is the risk-free rate, and $F_{k, t}, k \in[1,3]$, denote the three Fama and French factors (market, size, and book-to-market factors). ${ }^{23}$ Each month, we estimate the factor loadings $\widehat{\beta_{j, k}}$ for each stock using monthly rolling regressions with a 60 month window requiring at least 24 monthly return observations. The regressions use the Dimson approach with a lag of one month in order to remove biases from thin trading in the estimations

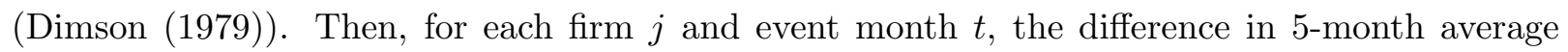
returns is computed as follows:

$$
r_{j, t}^{D i f f}=\frac{1}{5} \sum_{\tau=t+1}^{t+6} r_{j, \tau}^{*}-\frac{1}{5} \sum_{\tau=t-6}^{t-1} r_{j, \tau}^{*}
$$

We run separate Fama MacBeth cross-sectional return regressions for each real option proxy and for each of the up and the down switch samples. The regression model for month $t$ is

$$
r_{t}^{\text {Diff }}=\gamma_{0} \iota+\gamma_{1} R O_{t-1}+\eta_{t}
$$

where $r_{t}^{D i f f}$ is a vector of differences in average returns around the switch month $t, \iota$ is a vector of ones, and $R O_{t-1}$ is a vector of real option intensity values. Our model's predictions translate to tests that $\gamma_{0}>0$ and $\gamma_{1}>0$ (or $\gamma_{1}<0$ for inverse $R O$ proxies) for the up switch sample, and $\gamma_{0}<0$ and $\gamma_{1}<0$ (or $\gamma_{1}>0$ for inverse $R O$ proxies) for the down switch sample.

\section{Insert Table 5 here}

Table 1 reports the results. The estimates of $\gamma_{0}>0$ are positive for the up switch sample and negative for the down switch sample, and highly statistically significant in all specifications, offering evidence in agreement with the switch effect. The table also shows that the estimates

\footnotetext{
${ }^{23}$ The results using unadjusted returns are available from the authors upon request, but they are not materially different from the results using risk-adjusted returns.
} 
of $\gamma_{1}$ on total asset size, market equity value and age are positive for the down switch sample, and negative for the up switch sample, highlighting a positive correspondence between the switch effect and real option intensity.

Using categorical proxies for real option intensity offers consistent results with greater significance for the up switch sample than for the down switch sample. The exception is when the high vega dummy is used as a proxy, whose coefficient estimate is positive and significant for the down switch sample. However, the estimate for the combined small and high vega dummy is significant and consistent with the model's predictions for both the up and down switch samples. The coefficient estimate for the combined young and high vega dummy is also in favor of the model predictions for the up switch sample, while it lacks statistical significance for the down switch sample. Based on these results, we argue that equity vega alone is not a strong measure for real options unless it is combined with other proxies such as size and age. ${ }^{24}$

Using industry dummies as proxies for option intensity offers consistent results as well. While natural resources, high tech or bio tech industries alone do not offer statistically significant estimates, the all-growth option industry dummy offers an estimate consistent with the switch effect for the up switch sample.

Next, we investigate if the switch effect is stronger for firms with greater variability in $I V o l$ and that possess more growth options. We consider the variability in $I V o l(\overline{\Delta I V o l})$ and the interaction between option intensity and spread as explanatory variables for returns around the switch month. The regression model for month $t$ is

$$
r_{t}^{D i f f}=\gamma_{0} \iota+\gamma_{1} \overline{\Delta I V o l}+\gamma_{2} \overline{\Delta I V o l} \times R O_{t-1}+\eta_{t}
$$

where $r_{t}^{D i f f}, \iota$ and $R O_{t-1}$ are as defined previously, and $\overline{\Delta I V o l}$ is a vector of $\overline{\Delta I V o l_{j}}$. Our model's predictions translate to tests that $\gamma_{1}>0$ and $\gamma_{2}>0$ (or $\gamma_{2}<0$ for inverse $R O$ proxies) for the up switch sample, and $\gamma_{1}<0$ and $\gamma_{2}<0$ (or $\gamma_{2}>0$ for inverse $R O$ proxies) for the down switch sample.

Table reports the results. The table shows that the coefficient estimates for $\overline{\Delta I V o l}$ is positive for the up switch sample and negative for the down switch sample with statistically significant

\footnotetext{
${ }^{24}$ One way to view these results is that the levered equity of smaller and younger firms experience greater reactions to changes in operating risk than larger and more mature firms.
} 
results in virtually all of the regression specifications. Hence, the switch effect is stronger if $I V o l$ is more variable, consistent with our model's predictions.

The coefficient estimates for the interaction term between $\overline{\Delta I V o l}$ and $R O$ also support the model's predictions. The sign of the estimates are as predicted for age and size if measured as total assets in the up switch sample, while only size is significant in the down switch sample. The dummies for high future profit, sales and investment growth and their combinations with the small dummy all have positive estimates for the up switch sample with varying levels of significance. For the down switch sample, the estimates are not significant. As for the industry dummies, they are not statistically significant. A possible reason for this may be that industry classifications alone are weak proxies for real option intensity since firms within industries may vary widely in real option intensity. We conclude from these results that there is strong evidence for the switch effect which is more pronounced for more real option firms and which have more variable $I V o l$, consistent with our model's predictions.

\subsection{Positive $I V o l-R e t u r n$ Relation}

Our model also predicts that the positive $I V$ ol-return relation should be stronger for more option intensive firms and firms that experience larger changes in idiosyncratic volatility. In this section, we empirically test this prediction and provide supporting evidence.

We start by revisiting Grullon, Lyandres, and Zhdanov (2010) and estimating monthly return Eama and MacBeth ([.973) regressions on changes in idiosyncratic volatility and growth option intensity. The regression model for month $t$ is

$$
r_{t}-r_{f, t}=\gamma_{0} \iota+\gamma_{1} \Delta I V o l_{t}+\gamma_{2} \Delta I V o l_{t} \times R O_{t-1}+\gamma_{3} X_{t-1}+\eta_{t}
$$

where $r_{t}, r_{f, t}, \iota, \Delta I V o l_{t}, R O_{t-1}$ are as defined before, and $X_{t-1}$ is a matrix with columns of vectors of controls for firm size, book-to-market, past returns, trading volume and stock beta. Our model predictions translate to tests that $\gamma_{1}>0$ and $\gamma_{2}>0\left(\gamma_{2}<0\right.$ for inverse $R O$ proxies $)$

\section{Insert Table $\square$ here}


Table $\mathbb{\square}$ reports the results. Unsurprisingly, the coefficient estimates for stock beta and $\log$ book-to-market are both significantly positive, while the coefficient for log size are significantly negative in all specifications. The coefficient for trading volume is highly significant and positive, consistent with Karpoft (एप87) and Grullon, Lyandres, and Zhdanov (णㅣ). The coefficient for the past six month cumulative returns is insignificant and negative in all specifications, and consistent with some specifications reported in Cooper, Huseyin, and Schill (खण0) and Grullon, Lyandres, and Zhdanov (एण⿰亻) ${ }^{25}$

The table also reports a highly significant and positive $I V$ ol-return relation $\left(\gamma_{0}>0\right)$ for all specifications. As for the relation with respect to option proxies, firm size (both equity market value and total asset value) offers highly significant and negative estimates of $\gamma_{2}$. While $\gamma_{2}$ has the predicted negative sign for age, it is not statistically significant.

Focusing on the categorical variables for real option intensity, the $\gamma_{2}$ estimates for the high equity vega dummy is positive and highly statistically significant. This result is interesting because equity vega is the only proxy for real option intensity that is not necessarily related to growth. The high investment and high sales growth dummies also offer similar results. While the high profit growth dummy estimate is not significant, the combined high profit growth and small dummy has a highly significant and positive $\gamma_{2}$ estimate. Similar results apply to the combined dummies for high investment growth, high sales growth, and high equity vega dummies when combined with the small size dummy, implying that combining option proxies may capture real option intensity better.

Focusing on the industry dummies, while the $\gamma_{2}$ estimates are positive for natural resources, high technology and bio technology firms, only the natural resources industry dummy offers statistically significant results. However, the all-growth industry dummy has a highly significant and positive estimate in line with the predictions. In sum, the results thus far support a positive IVol-return relation that is stronger for more option intensive firms. These results are consistent with the findings in Grullon, Lyandres, and Zhdanov (

Next, our model also predicts that the positive $I V$ ol-return relation should be stronger for more real option intensive firms and firms with larger variability in idiosyncratic volatility. To test

\footnotetext{
${ }^{25}$ Grullon, Lyandres, and Zhdanov show that the coefficient on past returns is sensitive to the set of other independent factors included in Fama Macbeth regressions.
} 
this novel prediction, we complement the work of Grullon, Lyandres, and Zhdanov by running additional regressions in which we include $\overline{\Delta I V o l}$ and its interaction with real option proxies as explanatory variables:

$$
r_{t}-r_{f, t}=\gamma_{0} \iota+\gamma_{1} \overline{\Delta I V o l}+\gamma_{2} \Delta I V o l_{t}+\gamma_{3} \overline{\Delta I V o l} \times \Delta I V o l \times R O+\gamma_{3} X_{t-1}+\eta_{t}
$$

where $r_{t}, r_{f, t}, \iota, \Delta I V o l_{t}, R O_{t-1}, X_{t-1}$ and $\overline{\Delta I V o l}$ are as defined previously. Our model prediction translates to tests that $\gamma_{3}>0$ (or $\gamma_{3}<0$ for inverse $R O$ proxies).

\section{Insert Table 8 here}

The results are reported in Table $\boldsymbol{\nabla}$. The table reports estimates of $\gamma_{3}$ that are highly significant and positive (negative for inverse real option proxies) for virtually all the regression. The only exceptions apply when age and the dummies for young, small and young, and young and high vega are used where the results are statistically insignificant. The remainder of the table reports the results for the industry dummies. While $\gamma_{3}$ estimates are positive for natural resources, high technology and bio technology firms, only natural resources offers significant results. However, the all-growth industry dummy offers highly significant results in line with the predictions.

Collectively, the results are in strong agreement with our model. The positive IVol-return relation is more pronounced for more real option firms and firms that experience larger variability in idiosyncratic volatility.

\subsection{The Negative IVol-Return Relation}

Ang, Hodrick, Xing, and Zhang (2006) report that portfolios of high IVol stocks significantly under-perform their low $I V o l$ counterparts. Our model predicts that this negative $I V$ ol-return relation should be more pronounced for more real option intensive firms and firms with larger IVol spreads. We test this prediction and provide empirical support in this section.

At the end of each June, we sort and rank firms into three equally-sized groups by each one of our real option proxies, and separately by $I V o l .{ }^{26}$ Then, we compute value-weighted portfo-

\footnotetext{
${ }^{26}$ For the categorical real option proxies, firms are separated into two groups according to the value of the
} 
lio returns for each of the two-way classifications of $I V o l$ and option intensity and assess their performance over the following month. All portfolios are rebalanced monthly. This approach corresponds to the 1/0/1 (formation period/waiting period/holding period) strategy of Ang, Hodrick. Xing, and Zhang (2006) which most of their analysis is concentrated on.

The performance of the portfolios are assessed on a risk-adjusted basis relative to the Fama and French 3 factor model:

$$
r_{t}-r_{f, t}=\gamma_{0}+\gamma_{1} M K T R F_{t}+\gamma_{2} S M B_{t}+\gamma_{3} H M L_{t}+\epsilon_{t}
$$

where $r_{t}$ is the portfolio return, $r_{f, t}$ is the riskless rate, $M K T R F, S M B$, and $H M L$ are the Eama and French ([.993) three factors that proxy for the market risk premium, size and bookto-market factors respectively. ${ }^{27}$ In order to investigate the extent to which real option intensity contributes to the negative $I V o l$-return relation, we also estimate the regression for the zero-cost $I V o l$ portfolios for each rank of option intensity. ${ }^{28}$ A larger intercept $\gamma_{0}$ estimate translates to a greater average risk-adjusted return.

\section{Insert Table $\mathbf{Q}$ here}

Tables $\mathbf{9}$ to $\mathrm{U}$ report the results. Each panel in the tables corresponds to a different real option proxy, with $I V$ ol ranks reported across columns. The last column of each panel reports the estimates for the zero-cost $I V o l$ portfolios. The real option ranks are listed down the rows. The reported estimates are annualized to facilitate the interpretation of the economic significance. All other reported figures are unadjusted.

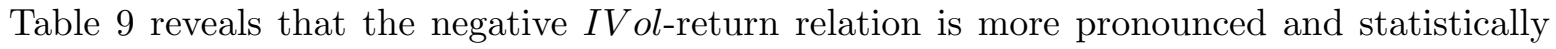
more significant for the two lowest firm size groups by total asset value. The negative $I V$ ol-return relation for the largest group is not significant. Size by market equity value and firm age offer similar patterns, lending strong support for our model predictions. The return relation is also stronger for high equity vega firms than for low vega firms. This finding is enlightening because

\footnotetext{
dummies.

${ }^{27}$ Portfolio-based tests with raw returns, and risk-adjusted return relative to the CAPM and the 4-factor model are also available upon request.

${ }^{28}$ For the zero-cost $I \mathrm{Vol}$ portfolios, we use portfolio returns instead of portfolio excess returns on the left hand side of regression (5.9).
} 
equity vega is the only option proxy that is not necessarily related to future growth opportunities.

\section{Insert Table 미 here}

The evidence for the negative $I V o l$-return relation is even stronger among small and high equity vega firms than for high equity vega firms alone. Hence, evidence for the negative IVolreturn relation is even stronger when proxies for real option intensity are combined, lending credence to our option based-explanation for the return relation. The other panels point to that conclusion as well. While the negative $I$ Vol-return relation is not conclusively stronger for high profit, high sale or high investment growth firms, it is stronger for these firms if they are also small in size, and similarly for younger firms and firms that are younger and have high equity vega.

In relation to the firms' industries, the negative IVol-return relation is more pronounced for natural resources and high technology stocks, while bio tech and all growth-industries offer inconclusive evidence. As mentioned earlier, industry membership alone may be a weak proxy for real option intensity because firms within industries can vary widely in their real option intensity. In sum, we find that there is considerable evidence that the $I V$ ol-return relation relates to real option intensity.

Next we investigate how the negative $I V$ ol-return relation relates to the spread in idiosyncratic volatility. In addition to the two-way independent sorts based on $I V o l$ and each of the real option proxies, we independently sort stocks into three equally-sized groups based on $\overline{\Delta I V o l}$. Then, for each of the two-way rank classifications of real option intensity and $\overline{\Delta I V o l}$, we assess the value-weighted returns of the zero-cost $I \mathrm{Vol}$ portfolios relative to the Fama and French 3 factor model.

\section{Insert Table ㅁ] here}

Tables $\mathbb{}$ and $\square 2$ report the results. For size and firm age, the negative $I V$ ol-return relation is monotonically stronger and more significant for the top $\overline{\Delta I V o l}$ group. The table also shows that the negative $I V o l$-return relation is stronger among the youngest firms and firms that have the largest $\overline{\Delta I V o l}$. These results support our predictions that the negative $I V$ ol-return relation 
should be more pronounced for growth firms that experience more extreme changes in $I V o l$. The table also reveals that the negative $I V$ ol-return relation seems to be more pronounced for larger firms among the top $\overline{\Delta I V o l}$ stocks. While these results are not in direct support of our model, the negative $I V$ ol-return remains both statistically and economically significant for smaller firms.

The main conclusions are similar for high profit, high sale and high investment growth firms. While there is a stronger negative $I V o l$-return relation for the high $\overline{\Delta I V o l}$ stocks independently of the real option characteristics, the return relation seems to be weaker for high future growth firms. One reason for these findings may be that the negative $I V$ ol-return relation could be confounded by the positive returns of high future growth stocks. This is likely to be the case if information on high future growth is reflected in stock returns during the portfolio evaluation period.

\section{Insert Table 피 here}

Now focusing on the combined real option proxies, Table 미 shows consistent results as well that the negative IVol-return relation is stronger for small and high growth, small and young, and small and high equity vega firms and high $\overline{\Delta I V o l}$ firms. In relation to industry membership, the table shows that the negative $I V$ ol-return relation is monotonically stronger and statistically more significant for larger $\overline{\Delta I V o l}$ independently of industry membership. Natural resources, bio tech and all-growth industry firms within the high $\overline{\Delta I V o l}$ have stronger negative $I V o l$-return relation, lending support for our model predictions. While high tech stocks exhibit a weaker

$I V o l$-return relation than low tech stocks within the high $\overline{I V o l}$ group, the return relation still remains significant for the high tech stocks.

Overall, these results demonstrate that the stocks of firms that experience more extreme changes in $I V o l$ and incorporate more real options exhibit stronger $I V o l$-return relations, lending support for our model's predictions. 


\section{Conclusions}

Recent empirical evidence shows that stock returns and idiosyncratic volatility are contemporaneously positively correlated (Duffed ([प995)), while others show that portfolios of high idiosyncratic volatility stocks (Ang, Hodrick, Xing, and Zhang (ए006)) underperform their low idiosyncratic volatility counterparts.

In this paper, we propose a unified economic explanation for the disparate findings, which hinges on a simple equity valuation model of a cross-section of firms involving growth options and stochastic idiosyncratic operating risk. More generally, we motivate why empirical work can indicate that idiosyncratic risks are priced in the cross-section of stock returns, even though the CAPM holds.

We introduce a 2-regime Markov switching process (see Guo, Miao, and Morelled (2005) and Hackbarth, Miao, and Morelled (2006)) to incorporate uncertainty in idiosyncratic operating risk. Growth option value is convex in the output price and it does not distinguish between systematic and idiosyncratic risks, a feature that contrasts starkly with the firm's assets-in-place. This gives rise to regime dependency of the firm's equity returns. In particular, we show that two key properties hold, which are sufficient conditions for the positive and negative $I V$ ol-return relations to hold. The first property is that returns and idiosyncratic volatility are exposed to the same risk factor, a property which arises immediately in a model of growth options where idiosyncratic operating risk is stochastic and drives the positive $I V o l$-return relation.

The second property is that the systematic volatility of returns falls when idiosyncratic risk rises. Idiosyncratic risk is by definition non-systematic. Hence, an increase in a firm's growth option value driven by a rise in idiosyncratic risk leads to a a fall in the proportion of the growth option value exposed to systematic risk. The firm's systematic risk then falls as systematic risk, which is precisely the second key property and leads to the negative $I V$ ol-return relation.

In summary, the time-series dynamics of the volatility structure in our model results in an interplay between returns and idiosyncratic return volatility consistent with what has been observed empirically in the cross-section of stocks. We verify our theoretical work with numerical simulations. To check that the underlying economics of our model is plausible, we empirically test the model's novel implications. Our empirical work shows that the positive and negative 
IVol-return relations are more pronounced for subsets of firms with more real options or which experience larger shifts in idiosyncratic volatility, which is supportive of our theoretical model.

Previous literature has relied on illiquidity and other market microstructure related explanations for the distributional properties of stock returns related to heteroskedasticity, discontinuities or jumps, and heavy tails. Our model has the capability to parsimoniously generate these features in return distributions from the operating environment that firms face, providing fertile grounds for additional research. ${ }^{29}$ Further research in this direction is highly merited.

Finally, our model suggests that jumps in stock returns should coincide with large changes in idiosyncratic return volatility in predictable ways, potentially shedding new insights on the threeway relation between stock returns, idiosyncratic return volatility and expected return skewness (Boyer, Mitton, and Vorkink (200 )). Furthermore, the features of our model may help establish predictability akin to return continuation amenable with the findings of Jegadeesh and Titman (ए9.93), and reversals reported in Jegadeesh (एप90). We leave these other interesting extensions for future research.

\footnotetext{
${ }^{29}$ The literature has recognized that asset returns must exhibit both stochastic volatility and discontinuous jumps to fit their empirical distributions (Das and Sundaram (एप999))
} 


\section{References}

Anderson, C. and L. Garcia-Feijoo. 2006. Empirical Evidence on Capital Investment, Growth Options, and Security Returns. Journal of Finance 171-194.

Ang, Andrew, Robert J. Hodrick, Yuhang Xing, and Xiaoyan Zhang. 2006. The Cross-Section of Volatility and Expected Returns. Journal of Finance.

. 2009. High Idiosyncratic Volatility and Low Returns: International and Further U.S. Evidence. Journal of Financial Economics 91:1-23.

Babenko, Ilona, Oliver Boguth, and Yuri Tserlukevich. 2013. Idiosyncratic Cash Flows and Systematic Risk. Working Paper, Arizona State University .

Bansal, Ravi and Yaron. 2004. Risks for the Long Run: A Potential Resolution of Asset Pricing Puzzles. Journal of Finance (4):1481-1509.

Berk, Jonathan, Richard Green, and Vasant Naik. 1999. Optimal Investment, Growth Options, and Security Returns. Journal of Finance. 54:1553-1607.

Bloom, Nicholas. 2009. The Impact of Uncertainty Shocks. Econometrica 77 (3):623-685.

Boyer, Brian, Todd Mitton, and Keith Vorkink. 2010. Expeced Idiosyncratic Skewness. Review of Financial Studies 23 (1):169-202.

Brennan, Michael and Eduardo Schwartz. 1985. Evaluating Nature Resource Investments. Journal of Business 58:135-157.

Brown, Gregory and Nishad Kapadia. 2007. Firm-Specific Risk and Equity Market Development. Journal of Financial Economics 84:358-388.

Bulan, Laarni. 2005. Real Options, Irreversible Investment and Firm uncertainty: New Evidence from U.S. Firms. Review of Financial Economics 14:255-279.

Caballero, Ricardo J. and Robert S. Pindyck. 1996. Uncertainty, Investment, and Industry Evolution. International Economic Review 37.

Carlson, Murray, Adlai Fisher, and Ron Giammarino. 2004. Corporate Investment and Asset Price Dynamics: Implications for the Cross-Section of Returns. Journal of Finance. 59:2577-2603.

. 2006. Corporate Investment and Asset Price Dynamics: Implications for SEO Event Studies and Long-run Performance. Journal of Finance. 61:1009-1034.

—. 2010. SEO Risk Dynamics. Review of Financial Studies. 24:4026-4077.

Chen, Joseph, Harrison Hong, and Jeremy C. Stein. 2001. Forecasting Crashes: Trading Volume, Past Returns, and Conditional Skewness in Stock Prices. Journal of Financial Economics 61:345-381.

Cooper, Ilan. 2007. Asset Pricing Implications of NonConvex Adjustment Costs and Irreversibility of Investment. Journal of Finance 61:139-170.

Cooper, Michael, Gulen Huseyin, and Michael Schill. 2008. Asset Growth and the Cross-Section of Stock Returns. Journal of Finance 1609-1652.

Daniel, Kent, David Hirshleifer, and Avanidhar Subrahmanyam. 1998. Investor Psychology and Security Market Under- Over-Reactions. Journal of Finance 1839-1886.

Das, Sanjiv Ranjan and Rangarajan K. Sundaram. 1999. Of Smiles and Smirks: A Term Structure Perspective. Journal of Financial and Quantitative Analysis 34 (2):211-239.

Dimson, Elroy. 1979. Risk Measurement When Shares are Subject to Infrequent Trading. Journal of Financial Economics 7:197-226.

Dixit, Avinash K. and Robert S. Pindyck. 1994. Investment under Uncertainty. Princeton University Press.

Duffee, Gregory R. 1995. Stock Returns and Volatility. A Firm-Level Analysis. Journal of Financial Economics 37:399-420. 
Fama, Eugene and Kenneth R. French. 1992. The Cross-Section of Expected Stock Returns. Journal of Finance 47:427-465.

- 1993. Common Risk Factors in the Returns on Common Stocks and Bonds. Journal of Financial Economics 25:2349.

—. 1996. Multifactor Explanations of Asset-Pricing Anomalies. Journal of Finance 51:55-84. 1997. Industry Costs of Equity. Journal of Financial Economics 49:153-193.

Fama, Eugene and James D. MacBeth. 1973. Risk Return, and Equilibrium: Empirical Tests. Journal of Political Economy 71:607-636.

Fu, F. 2009. Idiosyncratic Risk and the Cross-Section of Expected Stock Returns. Journal of Financial Economics 91:2437.

Garlappi, Lorenzo and Hong Yan. 2008. Financial Distress and The Cross-Section of Equity Returns. Working Paper .

Garleanu, Nicolae, Stavros Panageas, and Jianfeng Yu. 2012. Technological Growth and Asset Pricing. Journal of Finance 61.

Grullon, Gustavo, Evgeny Lyandres, and Alexei Zhdanov. 2010. Real Options, Volatility, and Stock Returns. Journal of Finance Forthcoming .

Guo, Xin, Jianjun Miao, and Erwan Morellec. 2005. Irreversible Investment with Regime Shifts. Journal of Economic Theory 122:37-59.

Hackbarth, Dirk, Jianjun Miao, and Erwan Morellec. 2006. Capital Structure, Credit Risk, and Macroeconomic Conditions. Journal of Financial Economics 82:519-550.

Hanson, Floyd B. 2007. Applied Stochastic Processes and Control for Jump-Diffusions: Modelling, Analysis and Computation. Society for Industrial and Applied Mathematics.

Huang, Wei, Qiangqiu Liu, S. Ghon Rhee, and Liang Zhang. 2009. Return Reversals, Idiosyncratic Risk, and Expected Returns. Review of Financial Studies .

Hull, John. 2011. Options, Futures, and Other Derivatives. Prentice Hall.

Jegadeesh, N. 1990. Evidence of Predictable Behavior of Security Returns. Journal of Finance 45:881-898.

Jegadeesh, N. and Sheridan Titman. 1993. Returns to Buying Winners and Selling Losers: Implications for Stock Market Efficiency. Journal of Finance 48:65-91.

Johnson, Timothy C. 2004. Forecast Dispersion and the Cross Section of Expected Returns. Journal of Finance 79:1957-1978.

Kapadia, Nishad. 2007. The Next Microsoft? Skewness, Idiosyncratic Volatility, and Expected Returns. Working Paper .

Karpoff, Jonathan. 1987. The Relation Between Price Changes and Trading Volume: A Survey. Journal of Financial and Quantitative Analysis 45:1161-1187.

Kogan, Leonid and Dimitris Papanikolaou. 2013. Firm Characteristics and Stock Returns: The Role of Investment-Specific Shocks. Review of Financial Studies 26:2718-2759.

Leahy, John and Toni Whited. 1996. The Effect of Uncertainty on Investment: Some Stylized Facts. Journal of Money, Credit, and Banking 28:64-83.

Lehmann, Bruce N. 1990. Residual Risk Revisited. Journal of Econometrics 45:71-97.

Lemmon, Michael and Jaime Zender. 2010. Debt Capacity and Tests of Capital Structure Theories. Journal of Financial and Quantitative Analysis 45:1161-1187.

Lintner, John. 1965. Security Prices, Risk, and Maximal Gains from Diversification. Journal of Finance 20:587-616.

MacDonald, Robert and Daniel Siegel. 1985. Investment and Valuation of Firms When There is an Option to Shut Down. International Economic Review 26:331-349. 
. 1986. The Value of Waiting to Invest. Quarterly Journal of Economics 101:707-727.

Majd, Saman and Robert S. Pindyck. 1987. Time to Build Option Value, and Investment Decisions. Journal of Financial Economics 18:7-27.

Merton, Robert C. 1974. On the Pricing of Corporate Debt: The Risk Structure of Interest Rates. Journal of Finance 29:449-470.

- 1992. Continuous-Time Finance. Basil Blackwell.

Newey, Whitney K. and Kenneth D. West. 1987. A Simple, Positive Semidefinite, Heteroskedastcity and Autocorrelation Consistent Covariance-Matrix. Econometrica 55:703-708.

Pindyck, Robert S. 1988. Irrevesible Investment, Capacity Choice, and the Value of the Firm. American Economic Review 78:969-985.

Pontiff. 2006. Costly Arbitrage and the Myth of Idiosyncratic Risk. Journal of Accounting and Economics $42: 35-52$.

Sagi, Jacob S. and Mark S. Seashole. 2007. Firm-Specific Attributes and the Cross-Section of Momentum. Journal of Financial Economics 84:389-434.

Spiegel, Matthew and Xiaotong Wang. 2006. Cross-sectional Variation in Stock Returns: Liquidity and Idiosyncratic Risk. Working Paper, Yale School of Management .

Tinic, Seha M. and Richard R. West. 1986. Risk, Return, and Equilibrium - A Revisit. Journal of Political Economy 94:126-147.

Zhang, Lu. 2005. The Value Premium. Journal of Finance. 60:67-103. 


\section{Appendix}

This Section provides proofs of the propositions and results stated in the paper.

\section{Proof of Proposition प}

Observe that

$$
G_{i, t}=E_{t}^{\mathbb{Q}}\left[e^{-r(\tau-t)}\left(\xi A_{\tau}-I\right) \mid s_{t}=i\right] .
$$

The basic asset pricing equation states that

$$
E_{t}^{\mathbb{Q}}\left[d G_{i, t}-G_{i, t} r d t \mid s_{t}=i\right]=0, t \leq \tau .
$$

We shall use $p_{t}=\ln P_{t}$ as the state variable. Under $\mathbb{Q}$, we have (using Ito's Lemma and Girsanov's Theorem)

$$
d p_{t}=\hat{\mu}_{p, i} d t+\sigma_{i} d \hat{B}_{t}
$$

where

$$
\begin{aligned}
\hat{\mu}_{p, i} & =\hat{\mu}-\frac{1}{2} \sigma_{i}^{2} \\
\sigma_{i} & =\sqrt{\left(\sigma_{i}^{i d}\right)^{2}+\left(\sigma^{s y s}\right)^{2}} \\
d \hat{B}_{t} & =\frac{\sigma_{i}^{i d}}{\sigma_{i}} d B_{t}^{i d}+\frac{\sigma^{s y s}}{\sigma_{i}} d \hat{B}_{t}^{s y s} .
\end{aligned}
$$

Hence, ([.2) implies the following ordinary differential equation system

$$
\frac{1}{2} \sigma_{i}^{2} \partial_{p_{t}}^{2} G_{i, t}+\hat{\mu}_{p, i} \partial_{p_{t}} G_{i, t}-r G_{i, t}+\lambda_{j}\left(G_{j, t}-G_{i, t}\right)=0, i, j \in\{L, H\}, j \neq i, t \leq \tau,
$$

where $\partial_{p_{t}}=\frac{\partial}{\partial p_{t}}$. We shall use the following notation: $I$ is the 2 by 2 identity matrix, $0_{2}$ is the 2 by 1 vector of zeros, $\operatorname{diag}\left(a_{1}, a_{2}\right)$ is the 2 by 2 diagonal matrix with $a_{1}, a_{2}$ along the diagonal, $\mathcal{D}_{p}^{i}=\frac{1}{2} \sigma_{i}^{2} \partial_{p_{t}}^{2}+\hat{\mu}_{p, i} \partial_{p_{t}}$, where $\hat{\mu}_{p, i}=\hat{\mu}-\frac{1}{2} \sigma_{i}^{2}, D=\operatorname{diag}\left(\mathcal{D}_{p}^{L}, \mathcal{D}_{p}^{H}\right), \Lambda$ is the generator matrix of the 2 state Markov chain, i.e. $\Lambda=\left(\begin{array}{cc}-\lambda_{H} & \lambda_{H} \\ \lambda_{L} & -\lambda_{L}\end{array}\right)$. Thus, we can write the ordinary differential equation system in matrix form as

$$
\left(D-r I_{2}+\Lambda\right)\left(\begin{array}{c}
G_{L} \\
G_{H}
\end{array}\right)=0_{2}
$$

When $p<p_{L}^{*}, t \leq \tau$, and so ([ष]) holds. The general solution is given by

$$
G_{i}=\sum_{m=1}^{4} h_{i m} e^{l_{m} p}
$$

where $l_{1}>l_{2}>0>l_{3}>l_{4}$ are the roots of the quartic in ([.]2).

To ensure that $G_{i} i \in\{L, H\}$ are finite as $p \rightarrow-\infty$, we set $h_{i 3}=h_{i 4}=0, i \in\{L, H\}$, so we use only 
the two positive roots: $l_{1}>l_{2}>0$.

$$
G_{i}=\sum_{m=1}^{2} h_{i m} e^{l_{m} p}
$$

Substituting the above expression into (ㄷ.8) gives

$$
\left(D-r I_{2}+\Lambda\right)\left(\begin{array}{ll}
h_{11} & h_{12} \\
h_{21} & h_{22}
\end{array}\right)\left(\begin{array}{c}
e^{l_{1} p} \\
e^{l_{2} p}
\end{array}\right)=0_{2}
$$

Simplifying gives

$$
\begin{aligned}
& \sum_{m=1}^{2} e^{l_{m} p}\left[h_{L m}\left(\frac{1}{2} \sigma_{L}^{2} l_{m}^{2}+\hat{\mu}_{p, L} l_{m}-\left(r+\lambda_{H}\right)\right)+h_{H m} \lambda_{H}\right]=0 \\
& \sum_{m=1}^{2} e^{l_{m} p}\left[h_{H m}\left(\frac{1}{2} \sigma_{H}^{2} l_{m}^{2}+\hat{\mu}_{p, H} l_{m}-\left(r+\lambda_{L}\right)\right)+h_{L m} \lambda_{L}\right]=0
\end{aligned}
$$

Consequently

$$
\frac{h_{H m}}{h_{L m}}=-\frac{\frac{1}{2} \sigma_{L}^{2} l_{m}^{2}+\hat{\mu}_{p, L} l_{m}-\left(r+\lambda_{H}\right)}{\lambda_{H}}=-\frac{\lambda_{L}}{\frac{1}{2} \sigma_{H}^{2} l_{m}^{2}+\hat{\mu}_{p, H} l_{m}-\left(r+\lambda_{L}\right)} .
$$

Thus

$$
h_{H m}=\epsilon\left(l_{m}\right) h_{L m},
$$

where

$$
\epsilon(l)=-\frac{q_{L}(l)}{\lambda_{H}}=-\frac{\lambda_{L}}{q_{H}(l)}
$$

Hence

$$
\begin{aligned}
G_{L} & =\sum_{m=1}^{2} h_{L m} e^{l_{m} p} \\
G_{H} & =\sum_{m=1}^{2} \epsilon\left(l_{m}\right) h_{L m} e^{l_{m} p} .
\end{aligned}
$$

Since $e^{p}=P$, we have

$$
\begin{aligned}
G_{L} & =\sum_{m=1}^{2} h_{L m} P^{l_{m}} \\
G_{H} & =\sum_{m=1}^{2} \epsilon\left(l_{m}\right) h_{L m} P^{l_{m}} .
\end{aligned}
$$

In the region $p \in\left[p_{L}^{*}, p_{H}^{*}\right)$, ([.]) still holds, but we also know that investment is immediate if the 
volatility state switches from high to low. Hence $G_{L, t}=\xi A_{t}-I$ just after the switch has occurred, and so

$$
\mathcal{D}_{p}^{L} G_{H}-r G_{H}+\lambda_{L}\left(\xi\left(\frac{e^{p}}{r-\hat{\mu}}-\frac{c}{r}\right)-G_{L}\right)=0
$$

The general solution of the above ordinary differential equation is given by

$$
G_{H, t}=\frac{\lambda_{L}}{r+\lambda_{L}}\left(\xi A_{t}-I\right)+\sum_{m=1}^{2} s_{m} e^{j_{m} p}
$$

where $j_{m}, m \in\{1,2\}$ are the roots of the quadratic (B.J8).

In the region $p \geq p_{H}^{*}$, investment will have occurred, and so

$$
G_{L, t}=\xi A_{t}, G_{H, t}=\xi A_{t}
$$

At the time of investment the above expressions need to be adjusted downward by subtracting the one-off investment cost of $I$.

Value matching at $p=p_{L}^{*}$ for $G_{L}$ implies that

$$
\lim _{p \uparrow p_{L}^{*}} G_{L}=\lim _{p \downarrow p_{L}^{*}} G_{L} .
$$

Value matching and smooth pasting at $p=p_{L}^{*}$ for $G_{H}$ implies that

$$
\begin{aligned}
\lim _{p \uparrow p_{L}^{*}} G_{H} & =\lim _{p \downarrow p_{L}^{*}} G_{H}, \\
\lim _{p \uparrow p_{L}^{*}} \frac{\partial G_{H}}{\partial p} & =\lim _{p \downarrow p_{L}^{*}} \frac{\partial G_{H}}{\partial p} .
\end{aligned}
$$

Value matching at $p=p_{H}^{*}$ for $G_{H}$ implies that

$$
\lim _{p \uparrow p_{H}^{*}} G_{H}=\lim _{p \downarrow p_{H}^{*}} G_{H}
$$

The above four boundary conditions allow us to determine the 4 constants of integration, $h_{L 1}, h_{L 2}, s_{1}, s_{2}$ in terms of the investment thresholds $P_{i}^{*}, i \in\{L, H\}$ and exogenous variables. In addition we have the two smooth pasting conditions, which ensure optimality of the investment thresholds:

$$
\begin{aligned}
\sum_{m=1}^{2} h_{L m} l_{m}\left(P_{L}^{*}\right)^{l_{m}-1} & =\frac{\xi}{r-\hat{\mu}} \\
\sum_{m=1}^{2} j_{m}\left(P_{H}^{*}\right)^{j_{m}-1}+\frac{\lambda_{L}}{r+\lambda_{L}} \xi & =\frac{\xi}{r-\hat{\mu}}
\end{aligned}
$$

In total, we have 6 equations in 6 unknowns:

$$
\sum_{m=1}^{2} h_{L m}\left(P_{L}^{*}\right)^{l_{m}}=\xi\left(\frac{P_{L}^{*}}{r-\hat{\mu}}-\frac{c}{r}\right)-I
$$




$$
\begin{aligned}
\sum_{m=1}^{2} \epsilon\left(l_{m}\right) h_{L m}\left(P_{L}^{*}\right)^{l_{m}}-\sum_{m=1}^{2} s_{m}\left(P_{L}^{*}\right)^{j_{m}} & =\frac{\lambda_{L}}{r+\lambda_{L}}\left[\xi\left(\frac{P_{L}^{*}}{r-\hat{\mu}}-\frac{c}{r}\right)-I\right] \\
\sum_{m=1}^{2} \epsilon\left(l_{m}\right) h_{L m} l_{m}\left(P_{L}^{*}\right)^{l_{m}}-\sum_{m=1}^{2} s_{m} j_{m}\left(P_{L}^{*}\right)^{j_{m}} & =\frac{\lambda_{L}}{r+\lambda_{L}} \xi \frac{P_{H}^{*}}{r-\hat{\mu}} \\
\sum_{m=1}^{2} s_{m}\left(P_{H}^{*}\right)^{j_{m}} & =\frac{r}{r+\lambda_{L}}\left[\xi\left(\frac{P_{H}^{*}}{r-\hat{\mu}}-\frac{c}{r}\right)-I\right] \\
\sum_{m=1}^{2} h_{L m} l_{m}\left(P_{L}^{*}\right)^{l_{m}} & =\xi \frac{P_{L}^{*}}{r-\hat{\mu}} \\
\sum_{m=1}^{2} s_{m} j_{m}\left(P_{H}^{*}\right)^{j_{m}} & =\xi\left(\frac{1}{r-\hat{\mu}}-\frac{\lambda_{L}}{r+\lambda_{L}}\right) P_{H}^{*} .
\end{aligned}
$$

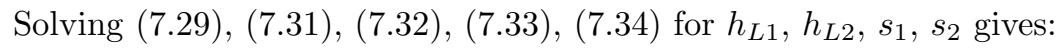

$$
\begin{aligned}
h_{L 1}= & \frac{\left(P_{L}^{*}\right)^{-l_{1}}}{l_{1}-l_{2}}\left\{\frac{\xi P_{L}^{*}}{r-\hat{\mu}}-l_{2}\left[\xi\left(\frac{P_{L}^{*}}{r-\hat{\mu}}-\frac{c}{r}\right)-I\right]\right\}, \\
h_{L 2}= & \frac{\left(P_{L}^{*}\right)^{-l_{2}}}{l_{1}-l_{2}}\left\{l_{1}\left[\xi\left(\frac{P_{L}^{*}}{r-\hat{\mu}}-\frac{c}{r}\right)-I\right]-\frac{\xi P_{L}^{*}}{r-\hat{\mu}}\right\}, \\
s_{1}= & \frac{\left(P_{H}^{*}\right)^{-j_{1}}}{j_{1}-j_{2}}\left\{\xi P_{H}^{*}\left(\frac{1}{r-\hat{\mu}}-\frac{\lambda_{L}}{r+\lambda_{L}}\right)-j_{2} \frac{r}{r+\lambda_{L}}\left[\xi\left(\frac{P_{H}^{*}}{r-\hat{\mu}}-\frac{c}{r}\right)-I\right]\right\}, \\
s_{2}= & \frac{\left(P_{H}^{*}\right)^{-j_{2}}}{j_{1}-j_{2}}\left\{j_{1} \frac{r}{r+\lambda_{L}}\left[\xi\left(\frac{P_{H}^{*}}{r-\mu}-\frac{c}{r}\right)-I\right]+\xi P_{H}^{*}\left(\frac{\lambda_{L}}{r+\lambda_{L}}-\frac{1}{r-\mu}\right)\right\} .
\end{aligned}
$$

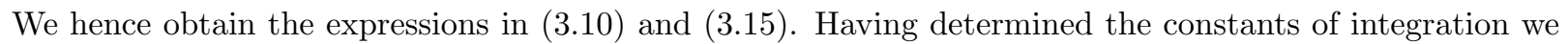

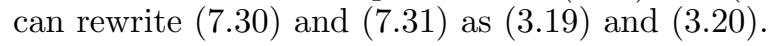

\section{Derivation of (इ.2丁)}

The return on assets-in-place is given by $d R_{A, t}=\frac{d A_{t}+\left(P_{t}-c\right) d t}{A_{t}}$. Applying Ito's Lemma gives (B.2D).

\section{Proof of Proposition [2]}

The return on a young firm's growth option is given by

$$
\frac{d G_{s_{t-}}}{G_{s_{t-}}}=\left(\Omega_{s_{t-}} \frac{d P_{t}}{P_{t}}+\frac{1}{2} \frac{P_{t}^{2}}{G_{s_{t-}}} \frac{\partial^{2} G_{s_{t-}}}{\partial P_{t}^{2}}\right)+\frac{G_{s_{t}}-G_{s_{t-}}}{G_{s_{t-}}} d N_{s_{t-} s_{t}, t}^{i d}
$$

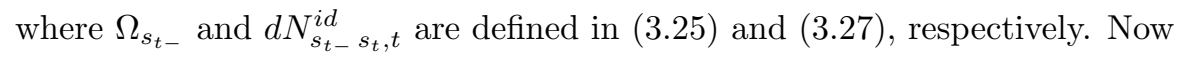

$$
\begin{aligned}
\frac{d G_{s_{t-}}}{G_{s_{t-}}} & =\Omega_{s_{t-}}\left(\mu d t+\sigma^{s y s} d B_{t}^{s y s}+\sigma_{s_{t-}}^{i d} d B_{t}^{i d}\right)+\frac{1}{2} \frac{P_{t}^{2}}{G_{s_{t-}}} \frac{\partial^{2} G_{s_{t-}}}{\partial P_{t}^{2}}\left(\left(\sigma^{s y s}\right)^{2}+\left(\sigma_{s_{t-}}^{i d}\right)^{2}\right) d t \\
& +\frac{G_{s_{t}}-G_{s_{t-}}}{G_{s_{t-}}} d N_{s_{t-} s_{t}, t}^{i d} \\
& =\left(\Omega_{s_{t-}} \mu+\frac{G_{s_{t}}-G_{s_{t-}}}{G_{s_{t-}}} \lambda_{s_{t-} s_{t}}+\frac{1}{2} \frac{P_{t}^{2}}{G_{s_{t-}}} \frac{\partial^{2} G_{s_{t-}}}{\partial P_{t}^{2}}\left(\left(\sigma^{s y s}\right)^{2}+\left(\sigma_{s_{t-}}^{i d}\right)^{2}\right)\right) d t
\end{aligned}
$$




$$
+\Omega_{s_{t-}}\left(\sigma^{s y s} d B_{t}^{s y s}+\sigma_{s_{t-}}^{i d} d B_{t}^{i d}\right)+\frac{G_{s_{t}}-G_{s_{t-}}}{G_{s_{t-}}} d M_{s_{t-} s_{t}, t}^{i d} .
$$

Now observe that for $P_{t}^{\max }<P_{L}^{*}$

$$
\Omega_{L}=w_{L}(P) l_{1}+\left(1-w_{L}(P)\right) l_{2}
$$

where

$$
w_{L}(P)=\frac{\delta_{L}\left(l_{2}\right)\left(\frac{P_{t}}{P_{L}^{*}}\right)^{l_{1}}}{\delta_{L}\left(l_{2}\right)\left(\frac{P_{t}}{P_{L}^{*}}\right)^{l_{1}}-\delta_{L}\left(l_{1}\right)\left(\frac{P_{t}}{P_{L}^{*}}\right)^{l_{2}}},
$$

and

$$
\Omega_{H}=w_{H}(P) l_{1}+\left(1-w_{H}(P)\right) l_{2},
$$

where

$$
w_{H}(P)==\frac{\epsilon\left(l_{1}\right) \delta_{L}\left(l_{2}\right)\left(\frac{P_{t}}{P_{L}^{*}}\right)^{l_{1}}}{\epsilon\left(l_{1}\right) \delta_{L}\left(l_{2}\right)\left(\frac{P_{t}}{P_{L}^{*}}\right)^{l_{1}}-\epsilon\left(l_{2}\right) \delta_{L}\left(l_{1}\right)\left(\frac{P_{t}}{P_{L}^{*}}\right)^{l_{2}}} .
$$

Note that

$$
\begin{aligned}
w_{H}(P)-w_{L}(P) & =\frac{\delta_{L}\left(l_{1}\right) \delta_{L}\left(l_{2}\right)\left(\frac{P}{P_{L}^{*}}\right)^{l_{1}+l_{2}}\left(\epsilon\left(l_{2}\right)-\epsilon\left(l_{1}\right)\right)}{\left(\epsilon\left(l_{1}\right) \delta_{L}\left(l_{2}\right)\left(\frac{P_{t}}{P_{L}^{t}}\right)^{l_{1}}-\epsilon\left(l_{2}\right) \delta_{L}\left(l_{1}\right)\left(\frac{P_{t}}{P_{L}^{t}}\right)^{l_{2}}\right)\left(\delta_{L}\left(l_{2}\right)\left(\frac{P_{t}}{P_{L}^{t}}\right)^{l_{1}}-\delta_{L}\left(l_{1}\right)\left(\frac{P_{t}}{P_{L}^{t}}\right)^{l_{2}}\right)} \\
& =\frac{\delta_{L}\left(l_{1}\right) \delta_{L}\left(l_{2}\right)\left(\frac{P}{P_{L}^{*}}\right)^{l_{1}+l_{2}}\left(q_{L}\left(l_{1}\right)-q_{L}\left(l_{2}\right)\right)}{\lambda_{H}\left(\epsilon\left(l_{1}\right) \delta_{L}\left(l_{2}\right)\left(\frac{P_{t}}{P_{L}^{t}}\right)^{l_{1}}-\epsilon\left(l_{2}\right) \delta_{L}\left(l_{1}\right)\left(\frac{P_{t}}{P_{L}^{*}}\right)^{l_{2}}\right)\left(\delta_{L}\left(l_{2}\right)\left(\frac{P_{t}}{P_{L}^{t}}\right)^{l_{1}}-\delta_{L}\left(l_{1}\right)\left(\frac{P_{t}}{P_{L}^{*}}\right)^{l_{2}}\right)} .
\end{aligned}
$$

After some tedious algebra, we can show that $l_{1}>l_{2}>0$ implies $q_{L}\left(l_{1}\right)>0>q_{L}\left(l_{2}\right)$, which in turn implies $w_{L}(P)<0<w_{H}(P)$, and so $\Omega_{L}>\Omega_{H}$ when $P_{t}^{\max }<P_{L}$.

Using the same approach, we can show that the fall in the growth option elasticity caused by a rise in idiosyncratic volatility is proportionally smaller than the idiosyncratic volatility increase, and so $\sigma_{L} \Omega_{L}<\sigma_{L} \Omega_{H}$, and also

$$
\Omega_{H} \mu+\frac{1}{2} \frac{P_{t}^{2}}{G_{H}} \frac{\partial^{2} G_{H}}{\partial P_{t}^{2}}\left(\left(\sigma^{s y s}\right)^{2}+\left(\sigma_{H}^{i d}\right)^{2}\right)>\Omega_{L} \mu+\frac{1}{2} \frac{P_{t}^{2}}{G_{L}} \frac{\partial^{2} G_{L}}{\partial P_{t}^{2}}\left(\left(\sigma^{s y s}\right)^{2}+\left(\sigma_{L}^{i d}\right)^{2}\right) .
$$




\section{Proof of Proposition 3}

The derivation of $(\mathbf{B} 2 \mathbb{d})$ is trivial: it merely states that the a young firm's systematic volatility is the weighted average of the systematic volatility of its assets-in-place and growth option.

To prove, (B.2Q) observe that

$$
G_{s_{t-}} \Omega_{s_{t-}}=P_{t} \frac{\partial G_{s_{t-}}}{\partial P_{t}}
$$

The same argument we used to prove $\Omega_{L}>\Omega_{H}$ when $P_{t}^{\max }<P_{L}$ also implies $G_{L} \Omega_{L}>G_{H} \Omega_{H}$. Since $G_{H}>$ $G_{L}$ (the standard option pricing result that volatility increases option value), we also have $V_{Y, H}>V_{Y, L}$. Hence, $\frac{G_{L}}{V_{L}} \Omega_{L}>\frac{G_{H}}{V_{H}} \Omega_{H}$. Since assets-in-place are independent of idiosyncratic volatility and $G_{H}>G_{L}$, we have $\frac{G_{H}}{V_{H}}>\frac{G_{L}}{V_{L}}$. Hence

$$
\frac{G_{H}}{V_{H}} \Omega_{H}-\frac{G_{L}}{V_{L}} \Omega_{L}+(1+L(P))\left(\frac{G_{L}}{V_{L}}-\frac{G_{H}}{V_{H}}\right)<0,
$$

which implies that $\sigma_{R_{Y}, H}^{s y s}<\sigma_{R_{Y}, L}^{s y s}$. 
Figure 1: Model's Properties and Solution: Dependence of Growth Option Value on the Idiosyncratic Volatility Regime

The figure shows growth option values for various values of $P$ across idiosyncratic volatility regimes and the exercise thresholds $P_{l}^{*}$ and $P_{h}^{*}$. The solid 45 degree line corresponds to the intrinsic value of the growth option. Option values in the high and low volatility states are depicted by dashed and dashed dotted curves, respectively. The exercise thresholds are depicted by the vertical dotted lines where the lower threshold corresponds to the exercise threshold $P_{l}^{*}$, and the higher threshold corresponds to the exercise threshold $P_{h}^{*}$. Panel (a) corresponds to the model solution with parameters $\sigma_{H}^{i d}=0.5, \sigma_{L}^{i d}=0.1$, panel (b) corresponds to the model solution with parameters $\sigma_{H}^{i d}=0.4, \sigma_{L}^{i d}=0.2$, and panel (c) corresponds to the model solution with parameters $\sigma_{H}^{i d}=0.3, \sigma_{L}^{i d}=0.3$.

(a) $\sigma_{H}^{i d}=0.5, \sigma_{L}^{i d}=0.1$

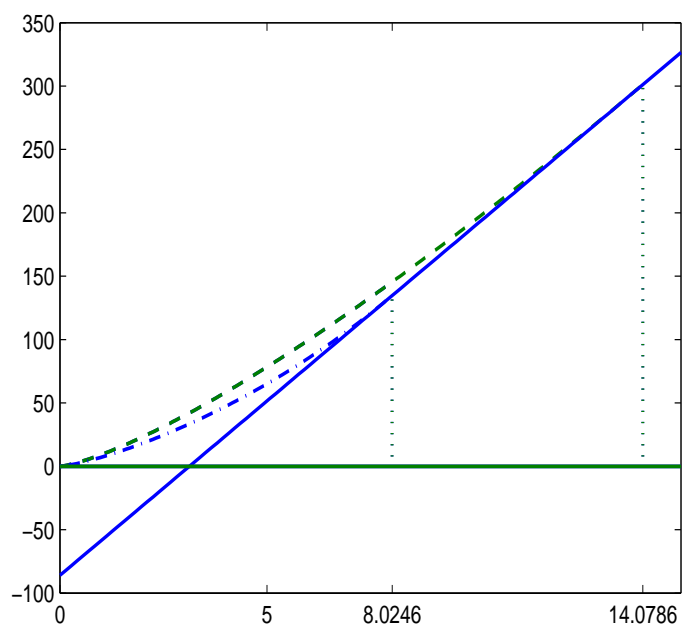

(b) $\sigma_{H}^{i d}=0.4, \sigma_{L}^{i d}=0.2$

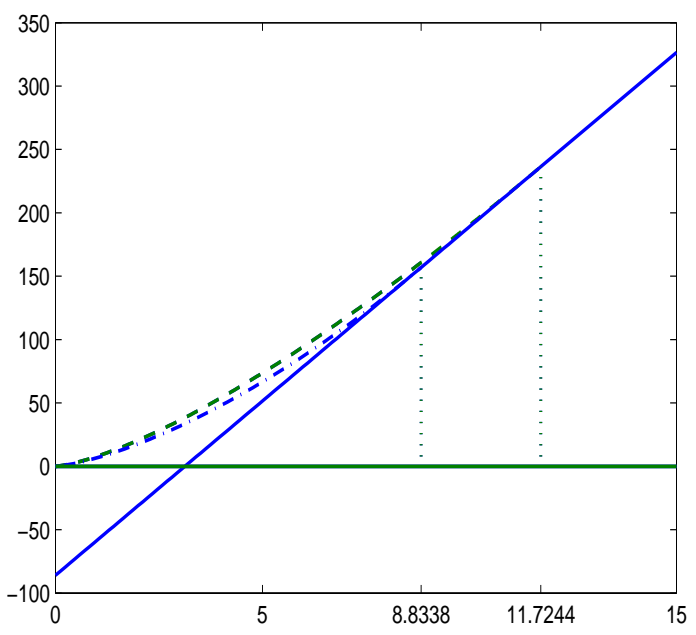

(c) $\sigma_{H}^{i d}=0.3, \sigma_{L}^{i d}=0.3$

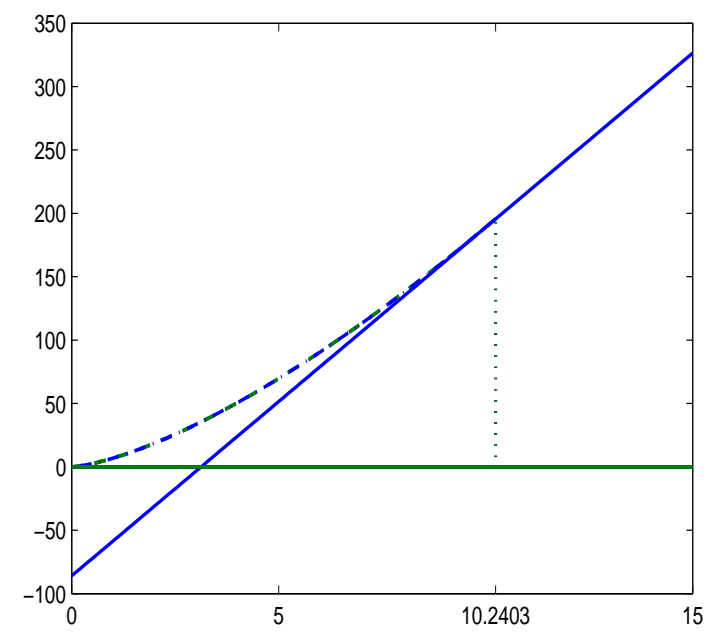


Figure 2: Model's Properties and Solution: Dependence of Return on Idiosyncratic Volatility Regime

The figure shows differences in the growth option's sensitivity to the systematic shock variable, the drift, the jump, and the diffusion terms of the option's value process between the high and low volatility regimes for various values of $P$ based on the model developed in the paper. Panel (a) shows differences in the systematic volatility $\left(\Omega_{H}-\Omega_{L}\right) \sigma^{\text {sys }}$, Panel (b) shows differences in total volatility $\Omega_{H} \sqrt{\left(\sigma^{s y s}\right)^{2}+\left(\sigma_{H}^{i d}\right)^{2}}-\Omega_{L} \sqrt{\left(\sigma^{s y s}\right)^{2}+\left(\sigma_{L}^{i d}\right)^{2}}$, Panel (c) shows differences in the continuous drift terms $\mu_{G, H}^{c}-\mu_{G, L}^{c}$, and Panel (d) shows differences in the jump terms $\frac{G_{L}-G_{H}}{G_{H}}-\frac{G_{H}-G_{L}}{G_{L}}$ between regimes. The figure shows separate results for each set of model parameter values $\left(\sigma_{H}^{i d}=0.5, \sigma_{P, L}^{i d}=0.1 ; \sigma_{P, H}^{i d}=0.4, \sigma_{P, L}^{i d}=0.2 ; \sigma_{P, H}^{i d}=\sigma_{P, L}^{i d}=0.3\right)$.

(a) Differences in systematic volatility terms

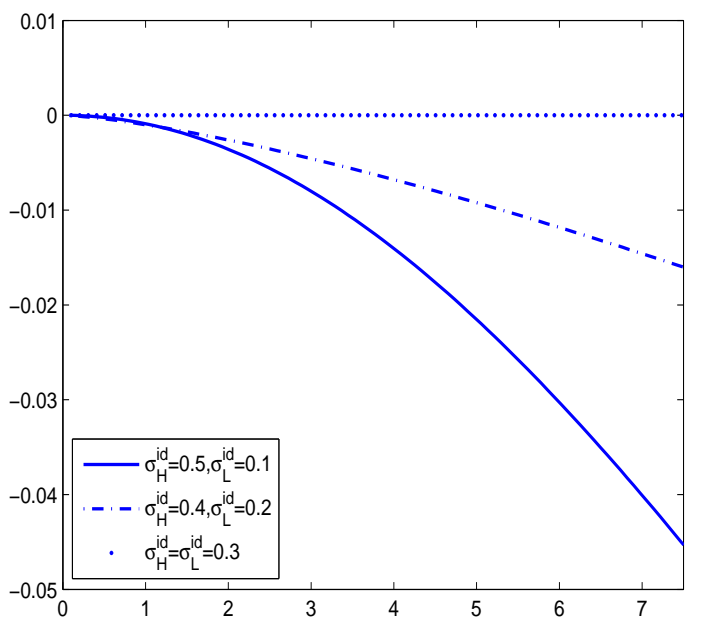

(c) Differences in drift terms

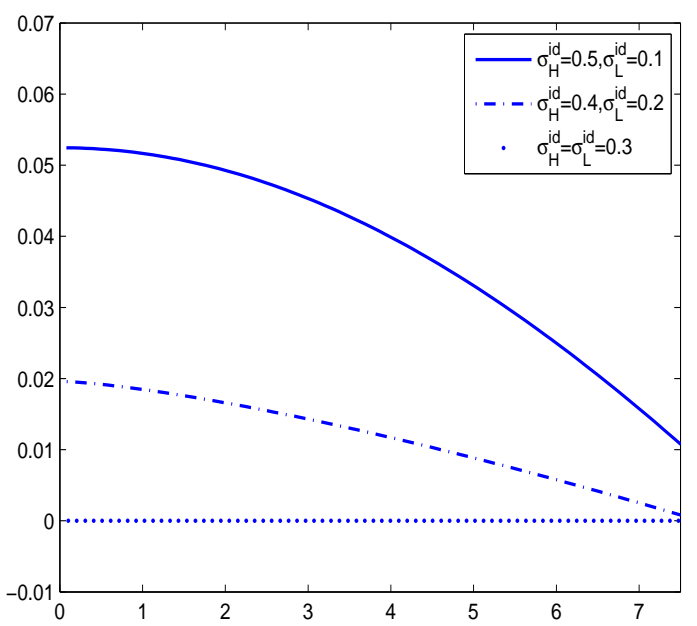

(b) Differences in diffusion terms

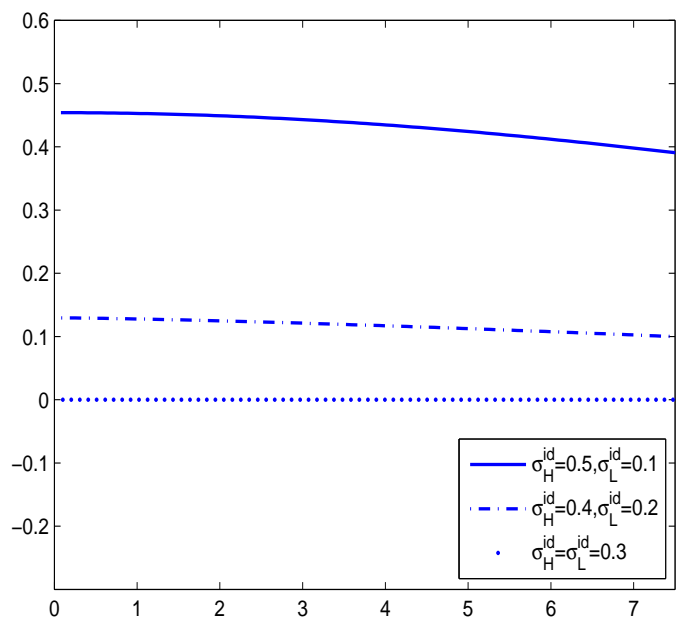

(d) Differences in jump terms

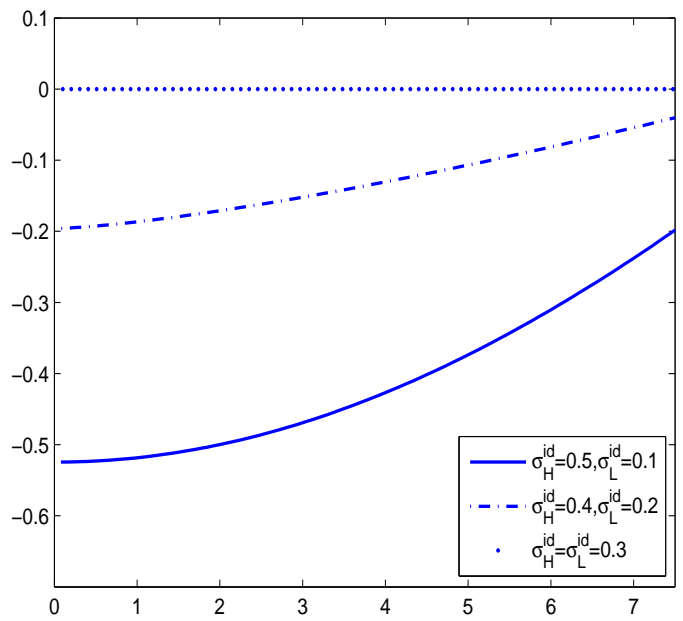




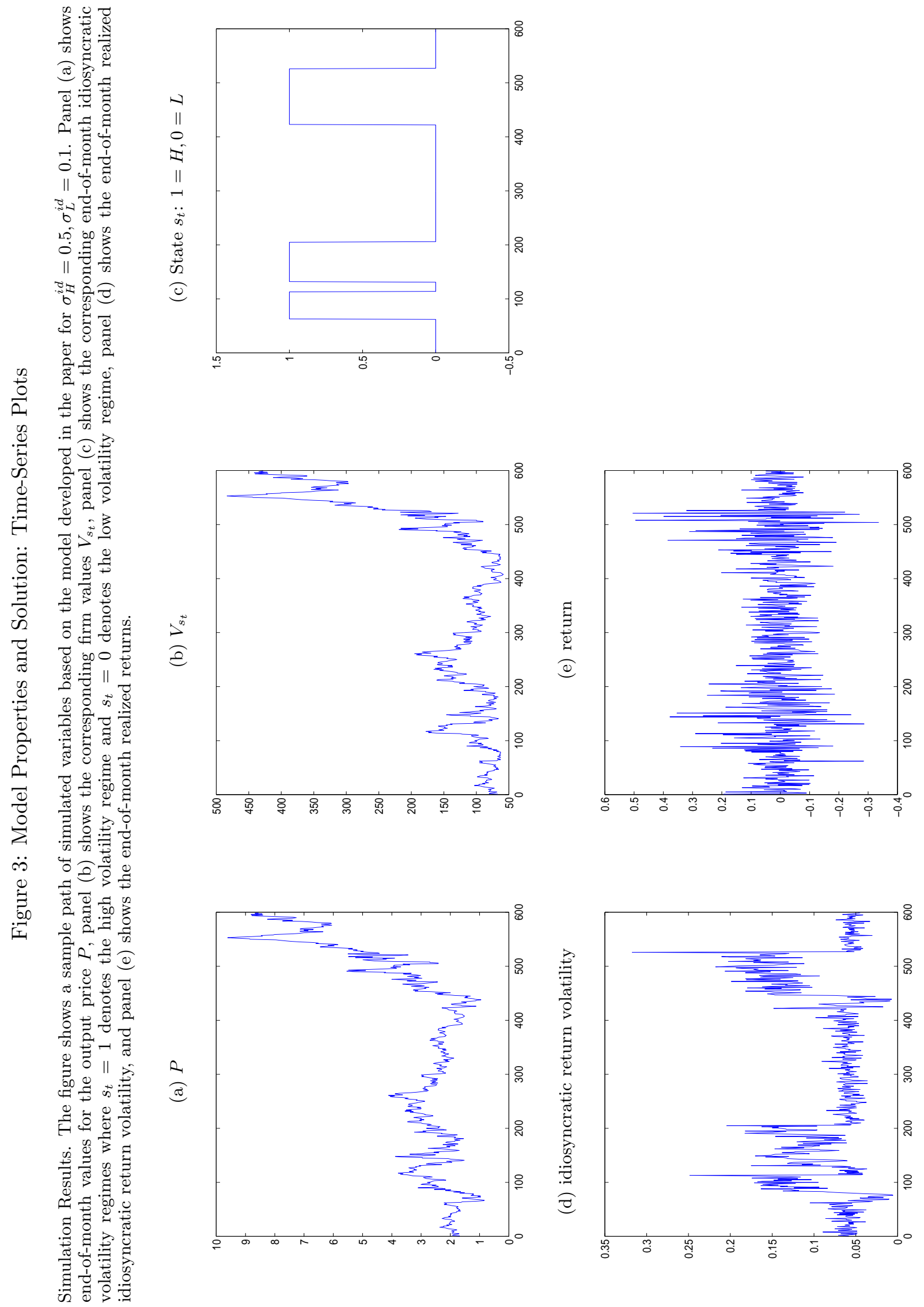


Figure 4: Simulation Results: Idiosyncratic Return Volatility Portfolio Returns

The figure shows the mean value-weighted returns of the portfolios formed after sorting stocks based on the past month return volatility $I \mathrm{Vol}$ using the simulated data based on the analytical solutions of the model developed in the paper. At the end of each month, stocks are sorted into five equally sized groups based on the past month $I V o l$, then value-weighted one-month holding period portfolio returns are computed. The portfolios are rebalanced at the end of each month. The figure shows separate results for each set of model parameter values $\left(\sigma_{H}^{i d}=0.5, \sigma_{L}^{i d}=0.1\right.$; $\left.\sigma_{H}^{i d}=0.4, \sigma_{L}^{i d}=0.2 ; \sigma_{H}^{i d}=\sigma_{L}^{i d}=0.3\right)$.

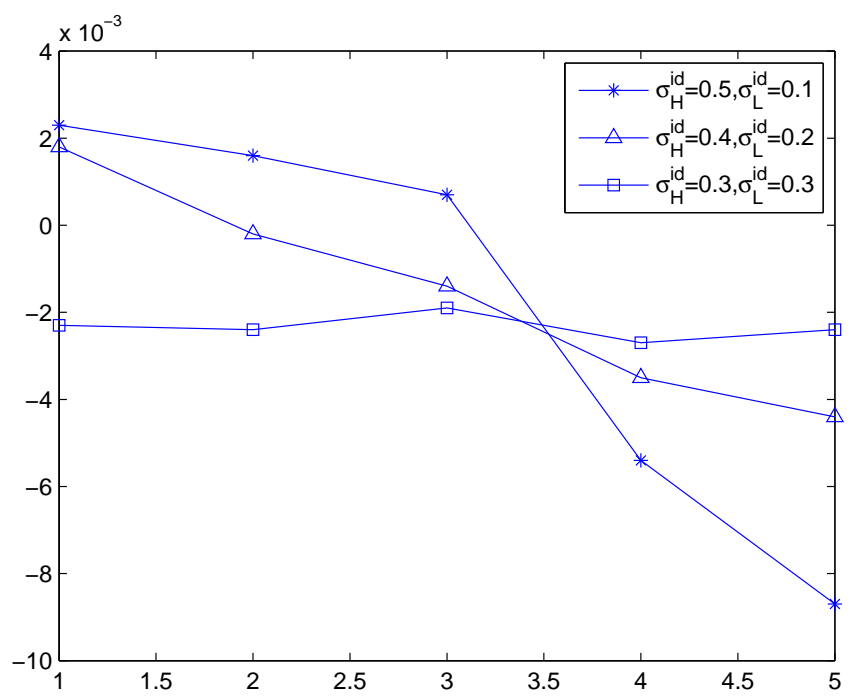


Table 1: Simulation Model Parameters

The table reports the parameter values used to solve and simulate the model developed in the paper. Base case parameter values are distinguished with an asterisk ${ }^{*}$ if more than one value is reported for a variable.

\begin{tabular}{llr}
\hline & \multicolumn{1}{c}{ Model Parameters } & Values \\
\hline Price Dynamics & Variable Description & $0.3,0.4,0.5^{*}$ \\
\hline$\sigma_{H}^{i d}$ & Output price idiosyncratic volatility in the high regime & $0.1^{*}, .02,0.3$ \\
$\sigma_{L}^{i d}$ & Output price idiosyncratic volatility in the low regime & 0.1 \\
$\lambda_{H}$ & Transition parameter from low to high volatility regime & 0.1 \\
$\lambda_{L}$ & Transition parameter from high to low volatility regime & 0.04 \\
$\mu$ & Drift term of the output price process & 0.15 \\
$\sigma^{s y s}$ & Systematic volatility of the output price process & Values \\
\hline Market & Variable Description & 0.05 \\
$r$ & Riskless rate & 0.1 \\
$\mu_{S}$ & Drift term of tradeable asset (Market) & 0.25 \\
$\sigma_{S}$ & Diffusion term of tradeable asset (Market) \\
Firm's Profit Function & Variable Description & Values \\
\hline$c$ & Variable cost per unit of output & 0.5 \\
$\xi_{Y}$ & Production scale for young Firms & 1 \\
$\xi$ & Difference in production scales between mature and young firms & 1.1 \\
$I$ & Investment cost & $1.5 \times(\xi-1) \times 20$ \\
Simulations & Variable Description & $r-\mu^{*}$ \\
\hline$N$ & Number of samples & $V$ alues \\
$n$ & Number of firms in each sample & 100 \\
$T$ & Number of years & 2500 \\
$n t$ & Number of trading days in each month & 50 \\
$\lambda_{\text {exit }}$ & Exit parameter for mature firms & 20 \\
& & 0.01 \\
\hline
\end{tabular}

Table 2: Simulation Results: Cross-Sectional Regressions

The table reports coefficient estimates for the regression model $r_{t}=\gamma_{0, t} \iota+\gamma_{1, t} \Delta I V o l_{t}+\eta_{t}$ in the first column of each panel, and estimates for the regression model $r_{t}=\gamma_{0, t} \iota+\gamma_{1, t} I V o l_{t-1}+\eta_{t}$ in the second column of the panels using the simulated data from the analytical solutions from the model developed in the paper. Panels (a), (b) and (c) report separate model estimates corresponding to the simulated samples where $\sigma_{H}^{i d}=0.5, \sigma_{L}^{i d}=0.1$, $\sigma_{H}^{i d}=0.4, \sigma_{L}^{i d}=0.2$ and $\sigma_{H}^{i d}=\sigma_{L}^{i d}=0.3$ respectively. T-statistics are reported in square brackets.

\begin{tabular}{|c|c|c|c|c|c|c|}
\hline \multirow[b]{2}{*}{ Intercept } & \multicolumn{2}{|c|}{ (a) $\sigma_{H}^{i d}=0.5, \sigma_{L}^{i d}=0.1$} & \multicolumn{2}{|c|}{ (b) $\sigma_{H}^{i d}=0.4, \sigma_{L}^{i d}=0.2$} & \multicolumn{2}{|c|}{ (c) $\sigma_{H}^{i d}=0.3, \sigma_{L}^{i d}=0.3$} \\
\hline & $\begin{array}{l}0.0056^{* * *} \\
{[40.1311]}\end{array}$ & $\begin{array}{l}0.0083^{* * *} \\
{[39.7255]}\end{array}$ & $\begin{array}{l}0.0056^{* * *} \\
{[44.5101]}\end{array}$ & $\begin{array}{l}0.0077^{* * *} \\
{[32.1002]}\end{array}$ & $\begin{array}{l}0.0050^{* * *} \\
{[27.9953]}\end{array}$ & $\begin{array}{c}-0.0030^{* * *} \\
{[-11.7416]}\end{array}$ \\
\hline$\Delta I V o l_{t}$ & $\begin{array}{l}0.1178^{* * *} \\
{[16.1998]}\end{array}$ & & $\begin{array}{l}0.0884^{* * *} \\
{[19.1783]}\end{array}$ & & $\begin{array}{c}0.0006 \\
{[0.7927]}\end{array}$ & \\
\hline$I V \mathrm{Ol}_{t-1}$ & & $\begin{array}{c}-0.1007^{* * *} \\
{[-39.2915]}\end{array}$ & & $\begin{array}{c}-0.0880^{* * *} \\
{[-31.0568]}\end{array}$ & & $\begin{array}{c}-0.0001 \\
{[-0.5524]}\end{array}$ \\
\hline
\end{tabular}


Table 3: Simulation Results: IVol Portfolio Returns

The table reports the mean $I V o l$ portfolio returns using simulated data based on the analytical solutions of the model developed in the paper. Stocks are sorted into five equally sized groups based on past month IVol, then value-weighted one-month holding period portfolio returns are computed. The portfolios are rebalanced at the end of each month. I Vol portfolios are reported across columns, and the last column reports the mean return of the zerocost $I V o l$ portfolio. The table reports separate results for each set of model parameter values $\left(\sigma_{H}^{i d}=0.5, \sigma_{L}^{i d}=0.1\right.$; $\left.\sigma_{H}^{i d}=0.4, \sigma_{L}^{i d}=0.2 ; \sigma_{H}^{i d}=\sigma_{L}^{i d}=0.3\right)$. T-statistics are reported in square brackets.

\begin{tabular}{ccccccc}
\hline & \multicolumn{5}{c}{ IVol Portfolios } \\
\cline { 2 - 7 } & \multicolumn{7}{c}{1} & 2 & 3 & 4 & 5 & $5-1$ \\
\cline { 2 - 7 } & & & & & & \\
& & & & & \\
$\sigma_{H}^{i d}=0.5, \sigma_{L}^{i d}=0.1$ & $0.0023^{* * *}$ & $0.0016^{* * *}$ & $0.0007^{* * *}$ & $-0.0054^{* * *}$ & $-0.0087^{* * *}$ & $-0.011^{* * *}$ \\
& {$[14.1267]$} & {$[8.7286]$} & {$[3.0931]$} & {$[-15.493]$} & {$[-25.1895]$} & {$[-33.7894]$} \\
$\sigma_{H}^{i d}=0.4, \sigma_{L}^{i d}=0.2$ & $0.0018^{* * *}$ & -0.0002 & $-0.0014^{* * *}$ & $-0.0035^{* * *}$ & $-0.0044^{* * *}$ & $-0.0062^{* * *}$ \\
& {$[11.1684]$} & {$[-0.9962]$} & {$[-5.7645]$} & {$[-11.3485]$} & {$[-14.3503]$} & {$[-21.0366]$} \\
$\sigma_{H}^{i d}=0.3, \sigma_{L}^{i d}=0.3$ & $-0.0023^{* * *}$ & $-0.0024^{* * *}$ & $-0.0019^{* * *}$ & $-0.0027^{* * *}$ & -0.0024 & 0 \\
& {$[-7.2206]$} & {$[-8.0168]$} & {$[-7.8058]$} & {$[-9.5375]$} & {$[-9.0741]$} & {$[-0.0484]$} \\
\hline
\end{tabular}

Table 4: Sample Summary Statistics

This table reports sample summary statistics for excess stock returns, idiosyncratic return volatilities $I V o l$, monthto-month $I V$ ol changes $\Delta I V o l$, and the real option intensity proxies. The sample period is from January, 1971 to December, 2010 for all the market-based variables. Excess return is the difference between end-of-month stock return and the risk-free rate. Stock return volatility $I V$ ol refers to the end-of-month volatility of the log daily returns risk-adjusted based on the Fama and French 3-factor model. Market equity and total assets are in millions of dollars. Firm age is expressed in months since the firms' first appearance on CRSP. Investment, profit and sale growths are expressed as the sum of the $t+2$ to $t+5$ growth rates where $t$ is the fiscal year of the return observation. vega is computed for each firm according to equation (??).

\begin{tabular}{|c|c|c|c|c|c|c|}
\hline market variables & Mean & StdDev & P5 & Median & P95 & $\mathrm{N}$ \\
\hline excess return & 0.009976 & 0.180828 & -0.22309 & -0.0041 & 0.272627 & 1041266 \\
\hline$I V o l$ & 0.029476 & 0.024979 & 0.0079 & 0.022782 & 0.072884 & 1038601 \\
\hline$\Delta I V o l$ & $-2.3 \mathrm{E}-05$ & 0.021096 & -0.02552 & -0.00011 & 0.026111 & 1035935 \\
\hline Real Option variables & Mean & StdDev & $\mathrm{P} 5$ & Median & P95 & $\mathrm{N}$ \\
\hline $\log$ (market equity) & 4.694734 & 2.106019 & 1.5389081 & 4.521163 & 8.389149 & 1040478 \\
\hline $\log ($ total assets $)$ & 4.804593 & 2.009753 & 1.789757 & 4.62188 & 8.352702 & 1041266 \\
\hline $\log ($ age $)$ & 3.953142 & 1.540425 & 0 & 4.290459 & 5.746203 & 1041266 \\
\hline investment growth & 0.996235 & 18.22423 & -0.64226 & 0.225036 & 2.237907 & 871778 \\
\hline profit growth & -0.55037 & 80.99137 & -6.71653 & 0.353252 & 4.689659 & 871779 \\
\hline sales growth & 1.579677 & 79.57993 & -0.46927 & 0.29381 & 1.83045 & 868519 \\
\hline vega & $2.84 \mathrm{E}-69$ & $1.49 \mathrm{E}-67$ & $9.63 \mathrm{E}-110$ & $9.89 \mathrm{E}-81$ & $1.88 \mathrm{E}-70$ & 1041104 \\
\hline
\end{tabular}




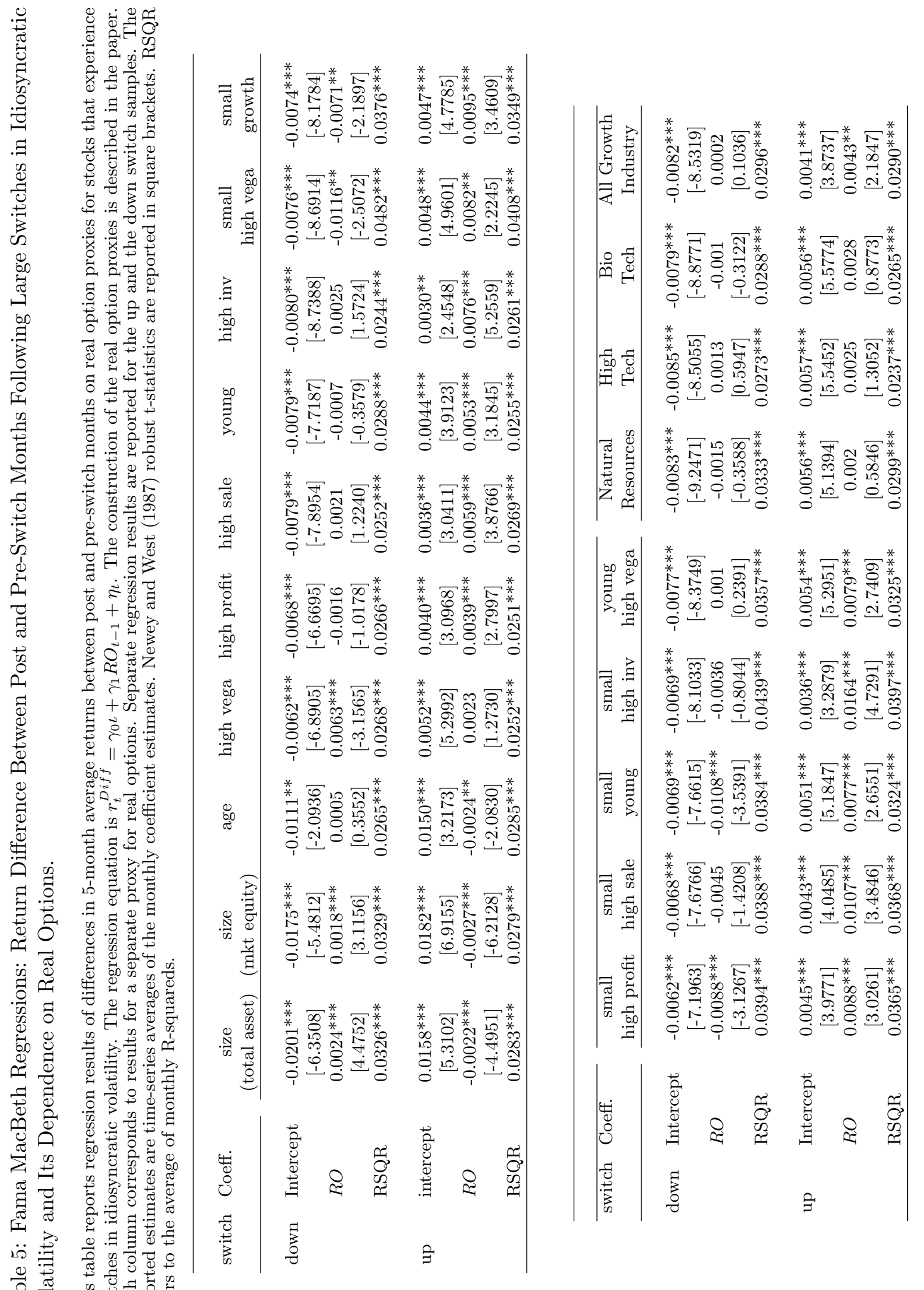




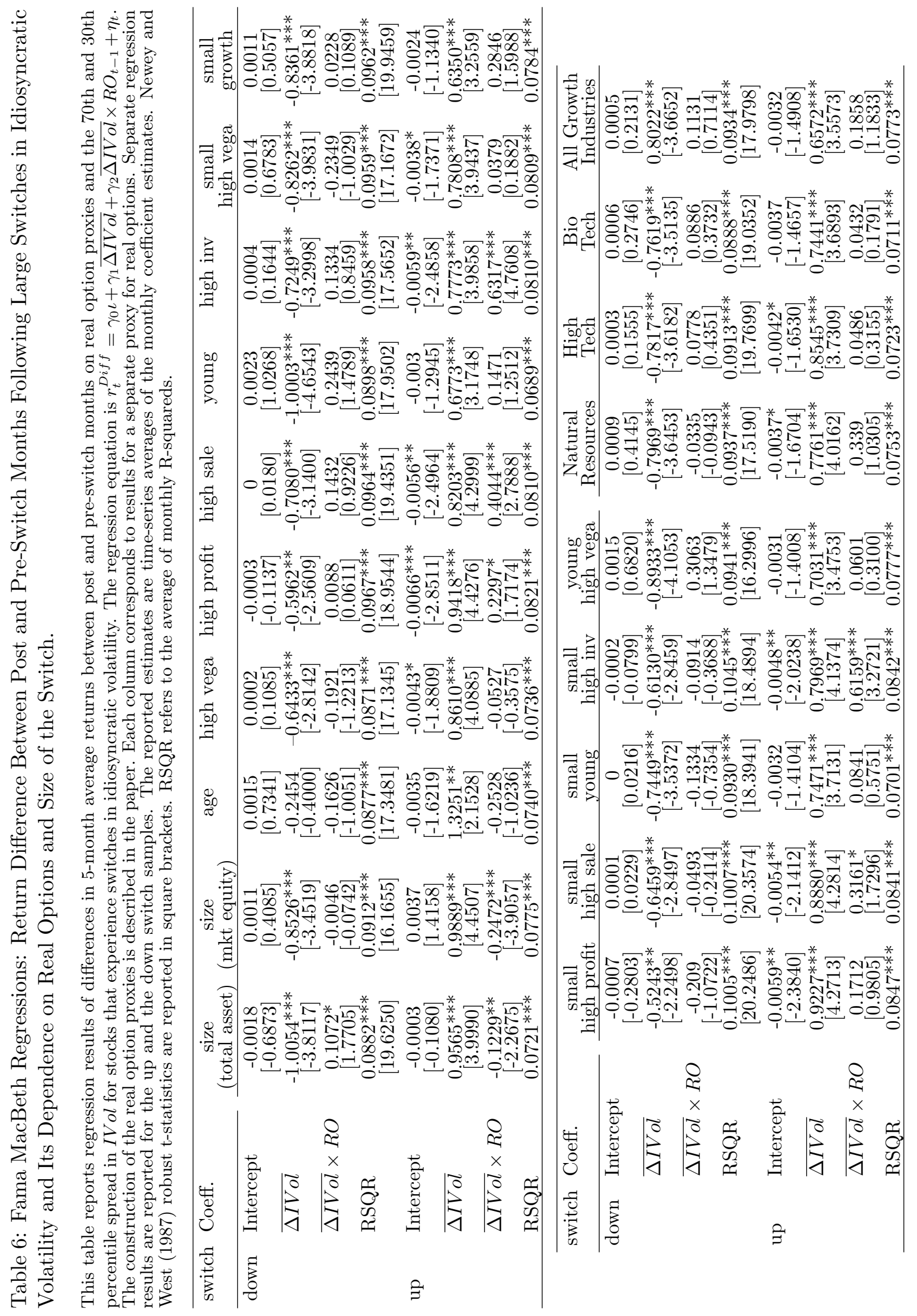




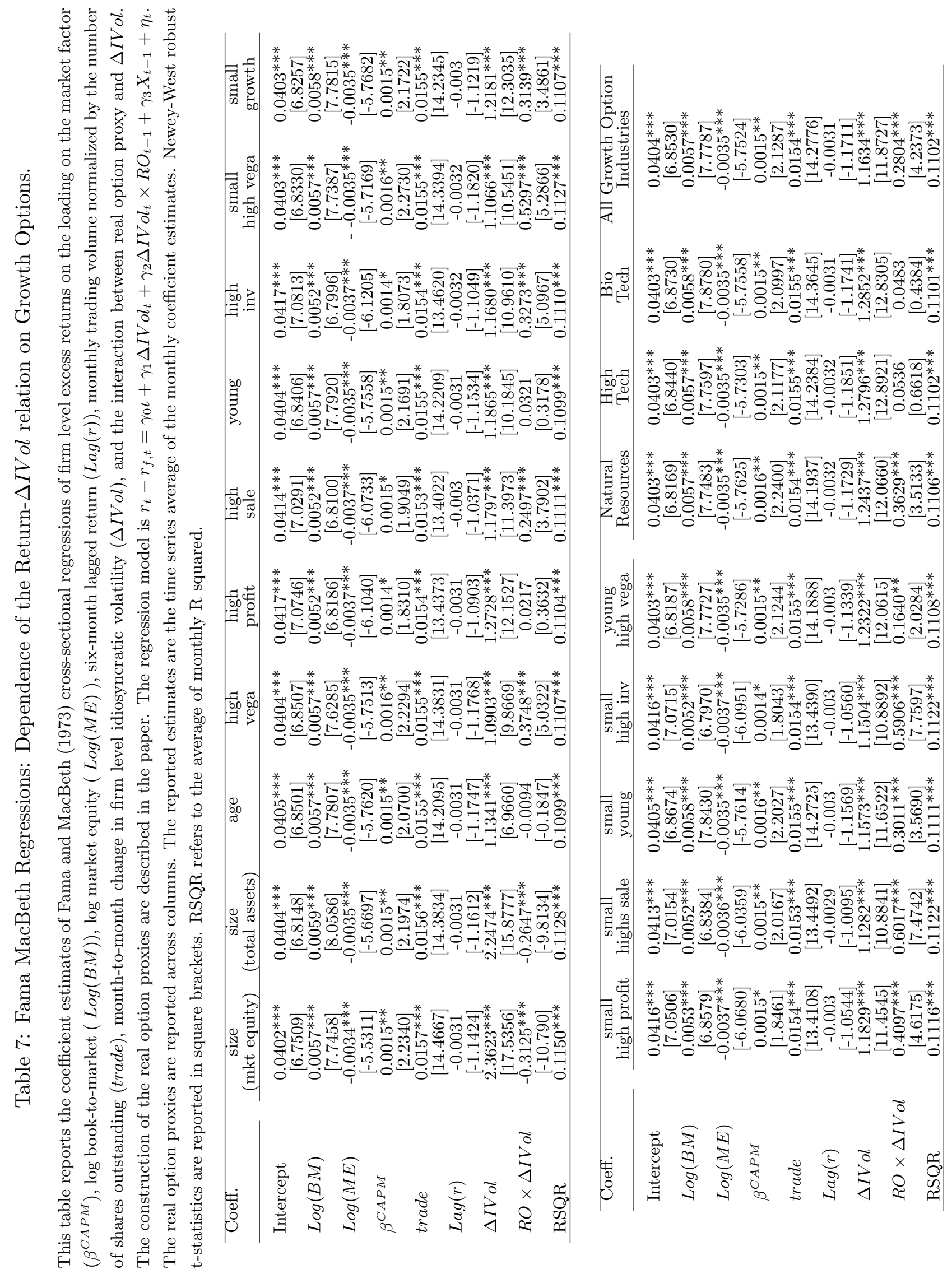




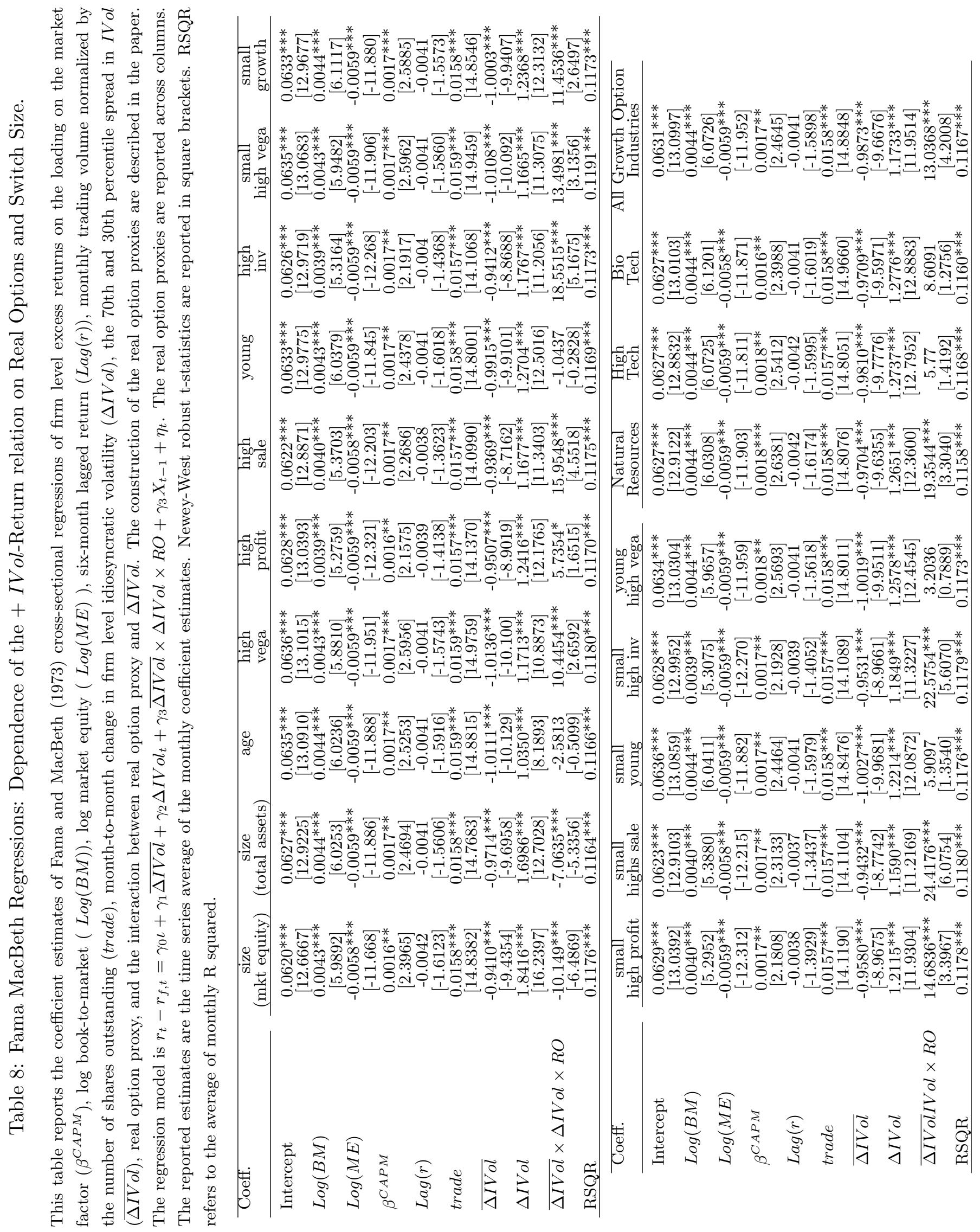




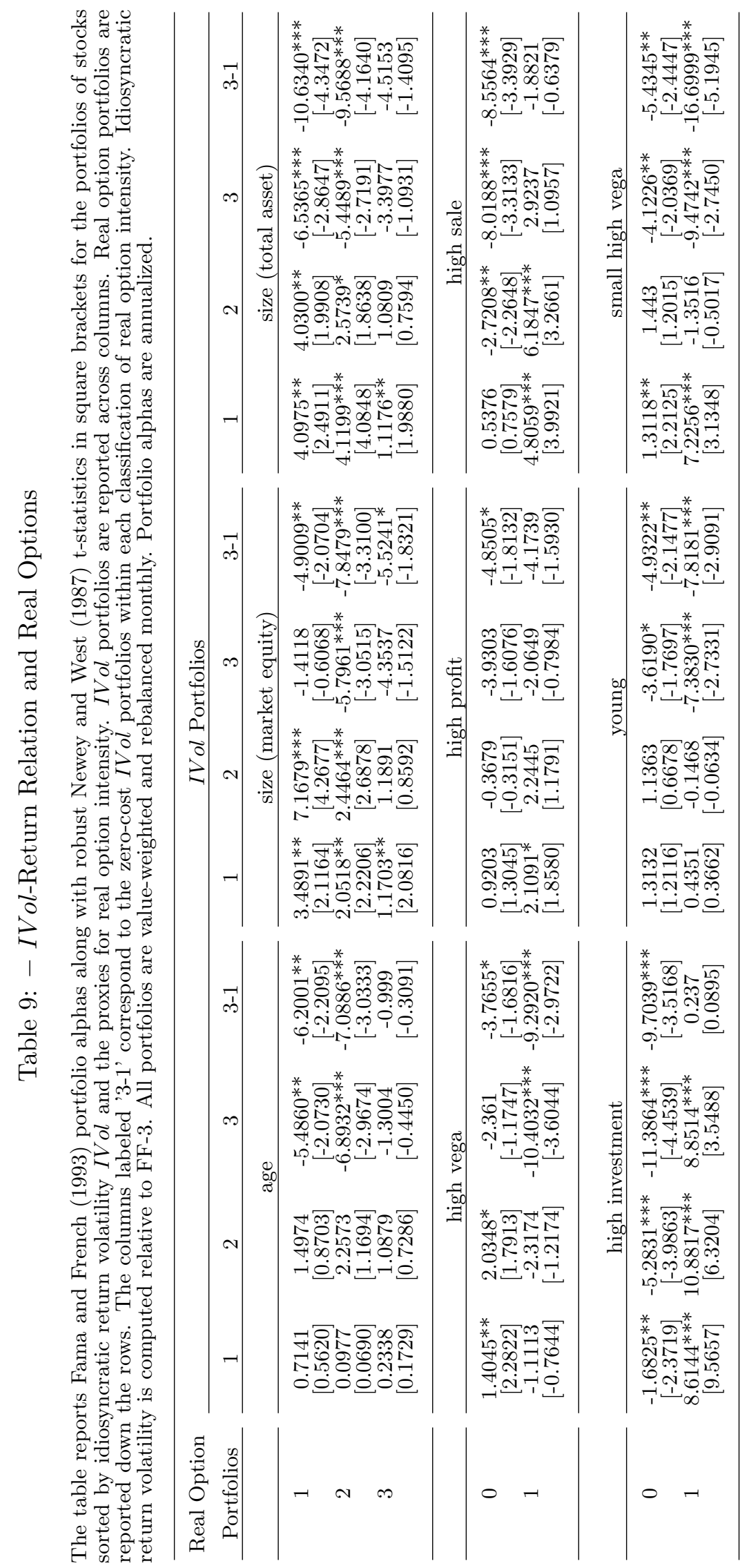




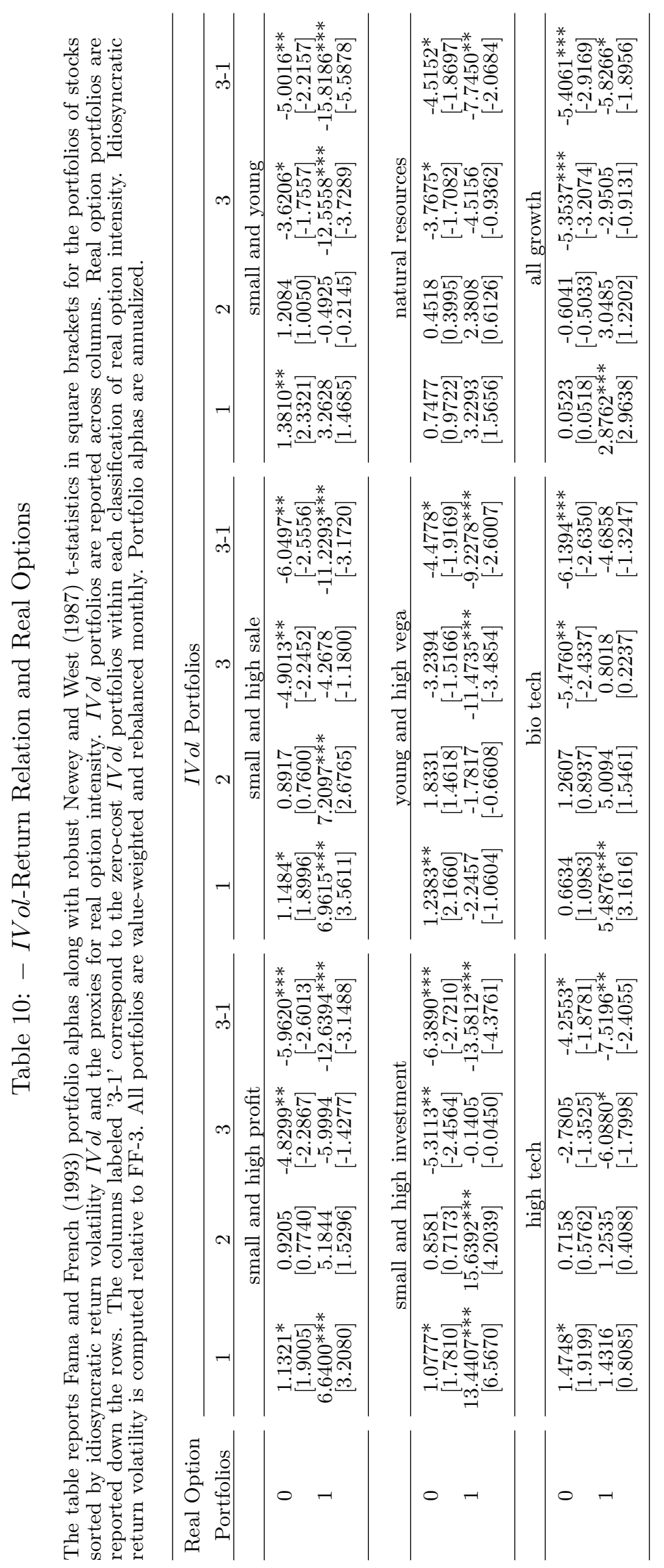




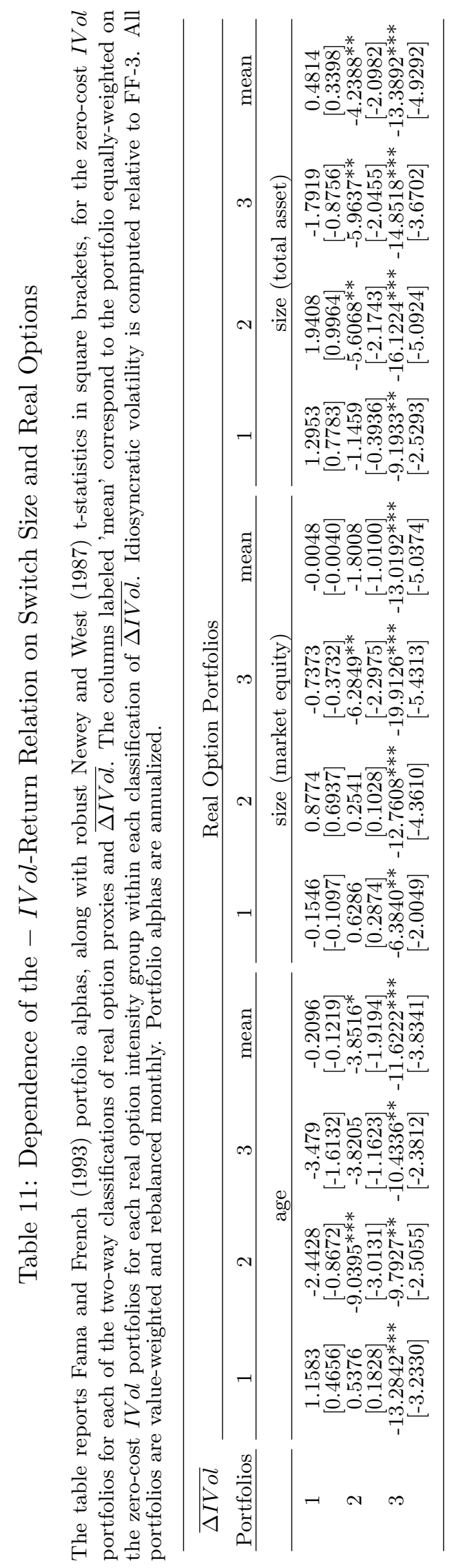




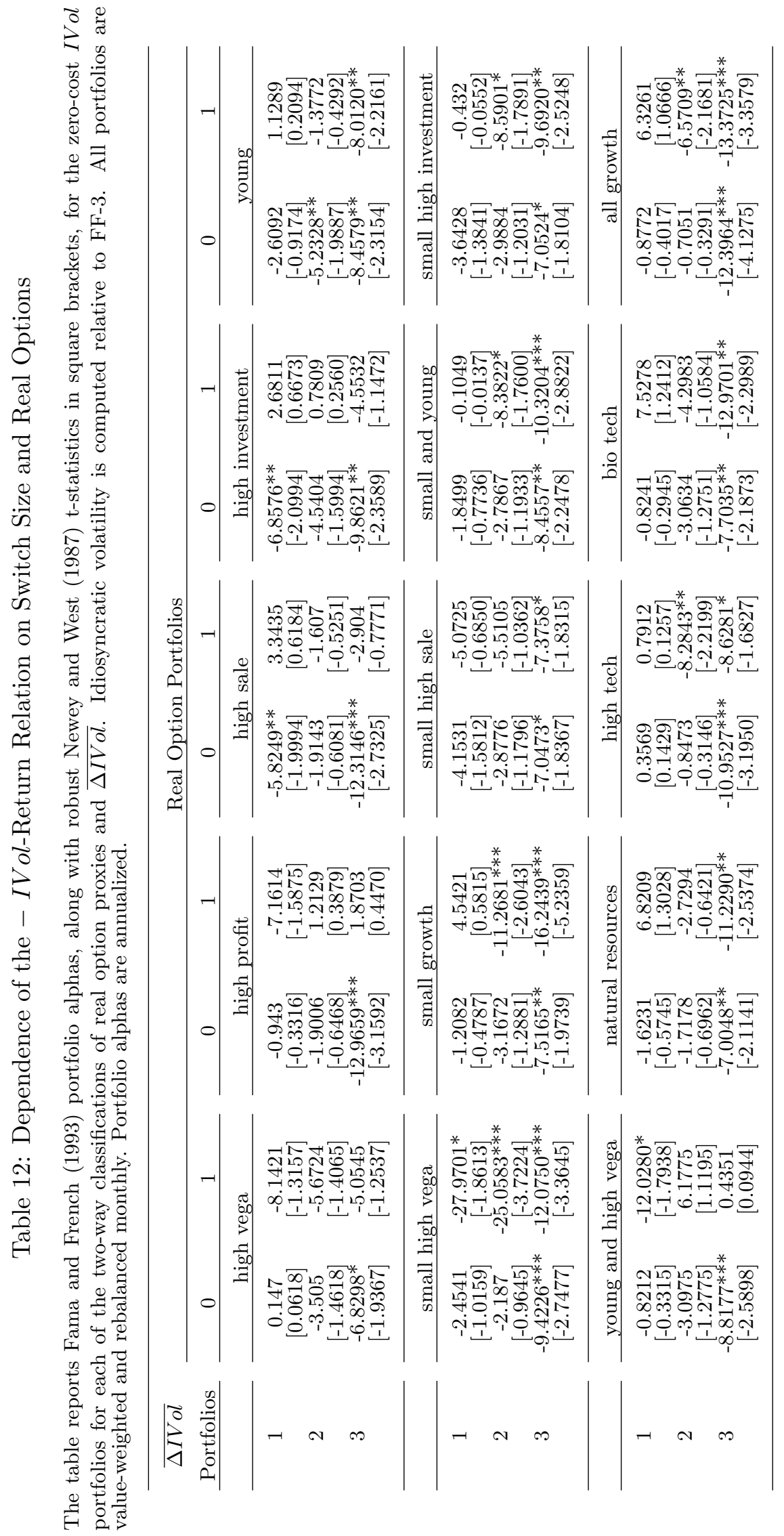

